\title{
An efficiency ranking of markets aggregated from single-object auctions
}

\author{
Eric Budish \\ Robert Zeithammer
}

August 11, 2011

\begin{abstract}
In a wide variety of economic contexts, collections of single-object auctions are used to allocate multiple substitutable goods. This paper studies how such collections of auctions aggregate into a multi-object auction market. We identify two features of auction-market design that enhance expected market efficiency: the individual auctions should be conducted in sequence, and information about all of the objects in the sequence should be revealed up front to the bidders. We then show that such an auction market is approximately efficient: specifically, its expected inefficiency is bounded above by the expected efficiency gain associated with adding one more bidder.
\end{abstract}

Keywords: Auctions, Market Design, Sequential Auctions, Information in Auctions, ecommerce, procurement, platforms, user-interface design, Bulow-Klemperer theorem

Acknowledgments: This paper combines and supersedes Zeithammer (2005) and Budish (2008). We are grateful to Susan Athey, Sushil Bikhchandani, Lucas Coffman, Itay Fainmesser, Drew Fudenberg, Ali Hortacsu, Sergei Izmalkov, Ian Jewitt, Paul Klemperer, Robin Lee, Greg Lewis, John Lewis, Ariel Pakes, Robert Ritz, Al Roth, Laura Serban, Birger Wernerfelt, and seminar participants at UT Austin, CERGE-EI, CU Boulder, Harvard, and UCLA for comments and suggestions. 


\section{Introduction}

In a wide variety of economic contexts, collections of single-object auctions are used to allocate multiple imperfectly substitutable objects. One important example is government procurement (e.g., highway construction): typically, each contract is allocated via its own sealed-bid auction, even though contracts are likely to be substitutable for suppliers due to capacity constraints. Another well-known example is the online auctioneer eBay, which uses the same single-object auction design for goods with substitutes, such as used automobiles and event tickets, as it does for the one-of-a-kind collectibles for which it was originally designed. Other examples include real-estate auctions, wine auctions, timber auctions, and offline wholesale used-auto auctions.

This paper studies how such collections of single-object auctions "aggregate up" into what we will call a (multi-object) auction market. Two features of auction-market design are remarkably constant among successful auction markets and often absent in failed ones. First, the individual auctions are organized so that bidders can easily participate in them in sequence. Second, the auctioneer provides information to bidders about the entire sequence of auctions known to him; that is, bidders know about future auctions when they must make decisions in current auctions. We show that each of these features enhances the expected allocative efficiency of the market as a whole. We then show that the market with auctions sequenced and information revealed, although not fully efficient, in a certain sense approximates full efficiency. That is, in our setting, an appropriately designed collection of single-object auctions generates nearly the same social surplus as would a more complicated but fully efficient combinatorial auction, such as Vickrey-Clarke-Groves (VCG). ${ }^{1}$

We begin by extending existing sequential auction theory (Engelbrecht-Wiggans 1994, Milgrom \& Weber 2000) to characterize the equilibrium of the sequential auction with future objects revealed. Our model is simple: $n$ bidders participate in a sequence of two second-price sealed-bid auctions. ${ }^{2}$ Bidders regard the objects as imperfect substitutes in the sense that they have different valuations of each object and unit capacity; for example, a consumer buying a used automobile on eBay values different cars differently and requires at most one car. Our main technical contribution is a proof that this dynamic game has an intuitive symmetric pure-strategy

\footnotetext{
${ }^{1}$ We do not model the choice between combinatorial auctions and collections of single-object auctions, which intuition suggests involves numerous tradeoffs. Instead, we focus on the efficiency of collections of single-object auctions, which we view as important in its own right due to the prevalence of such market institutions in practice.

2 The restriction to two objects is for tractability, and is commonly made in sequential auction settings (Black and de Meza 1992, Katzman 1999, Gale and Hausch 1994, and others).
} 
Bayes-Nash equilibrium in which participants bid their value for today's auction less a term that represents their expected surplus from tomorrow's auction-the opportunity cost of winning today. However, the expected surplus function itself is surprisingly subtle. The issue is that today's winning bid conveys information about the set of participating bidders in tomorrow's auction: since all bidders reduce their bids today as a function of their values of tomorrow's object, losing to a lower bid today makes higher competition tomorrow more likely. At the margin, each bidder therefore needs to assess the opportunity cost of winning today not only as a function of his valuation of tomorrow's object, but also as a function of the bid he submits today. Following Che and Gale (1998), we characterize the equilibrium surplus function in terms of isobids — sets of bidder types that submit the same first-round bid. The isobids turn out to be well behaved, facilitating the analysis of the comparative statics and the allocative efficiency of the auction. Surprisingly, the equilibrium involves first-stage trade almost surely, a consequence of the informational content of winning the first auction akin to the "loser's curse" (Holt and Sherman 1994, Pesendorfer and Swinkels 1997).

Having characterized the sequential auction with future objects revealed, we next turn to results about its efficiency relative to other auction-market designs. Our first efficiency result shows that revealing future objects increases the ex-ante expected efficiency of the sequence of auctions. Specifically, we compare the sequential auction with future objects revealed to a sequential auction with future objects hidden, first analyzed by Engelbrecht-Wiggans (1994). When future objects are hidden, bidders know a second auction will occur and know the distribution of potential valuations in the second auction, but they do not yet know their own specific valuations. The reason why we might expect the information about future objects to enhance efficiency is that informed bidders allocate their demand better across auctions: bidders with high values tomorrow can bid cautiously today, and bidders with low values tomorrow can bid aggressively today. We find that there are always some realizations of bidder values where revealing future objects lowers efficiency, but revealing future objects is indeed good for social welfare when averaged over all possible bidder valuations. ${ }^{3}$ Our proof utilizes a classic idea from the theory of single-object auctions with entry, namely, that the expected individual surplus of a participating bidder in a standard auction is equal to his expected contribution to social surplus

\footnotetext{
${ }^{3}$ It is immediate that revealing private valuations increases efficiency in a standard single-object auction. Moreover, revealing valuations also increases seller revenue as long as there are at least three bidders (Board, 2009).
} 
(McAfee and McMillan, 1987). In our sequential context, self-interested bidders shade their firstround bids precisely by their conditional expectation of second-round individual surplus, which we show is equal to their expected contribution to second-round social surplus. Thus, whenever the winner of the first object is not the bidder who values it most, society is better off in expectation with that "highest valuation" bidder participating in the second auction instead.

Our second efficiency result shows that regardless of information about the second object, sequencing itself increases the expected efficiency of the collection of auctions. We compare the sequential auction to an auction marketplace in which multiple individual auctions are separated, forcing each bidder to choose just one auction to participate in. For instance, imagine that the auctions take place simultaneously in separate rooms. Intuitively, we expect sequencing to be good for efficiency because it allows bidders to participate in more auctions; any bidder who loses the first auction can then participate in the second. As with the case of hidden future objects, it is always possible to find realizations of bidder values where running the auctions simultaneously-hence forcing bidders to choose ex-ante which one auction to participate in-actually increases allocative efficiency. But in expectation, we show that this kind of marketplace congestion is always bad for welfare.

Our last result shows that the sequential auction with future objects revealed is in a certain sense approximately efficient. More specifically, we show that the expected inefficiency of the sequential auction with future objects revealed is bounded above by the expected efficiency gain associated with adding one more bidder to the second auction. This bound is in the style of Bulow and Klemperer's (1996) bound on the revenue gain from using an optimally set reserve price. An interpretation is that the potential welfare gains from switching to a more sophisticated multi-object auction, such as VCG, are small in this environment.

Sequencing auctions and revealing future objects both seem like obvious design decisions in the context of auction markets for substitutes. Both practices have long been standard, for instance, at the classic auction houses Sotheby's and Christie's. Yet many real-life auction markets fail to do one or both of these things. For instance, the now-defunct Amazon and Yahoo auction marketplaces used soft-close ending times, meaning an auction ends only after some time elapses without a new bid (Roth and Ockenfels, 2001). This design made it difficult for bidders to guess which of two auctions would end first, and hence difficult to participate in both. Google Base's auctions - also defunct-were sorted by search-term closeness-of-fit rather than by 
ending time, making identifying, let alone participating in, the full sequence difficult for bidders. Moving against our efficiency result, in 2008 eBay switched from sorting auctions strictly by ending time (“Ending Soonest”) to a sort order based on a variety of features (“Best Match”); interestingly, eBay appears to have at least partly switched back in some product categories. ${ }^{4}$ Large wholesale car auctions in the United States often conduct several auctions concurrently, each in a separate "lane” (Tadelis and Zettlemeyer, 2011). Perhaps the starkest example of a nonsequential auction is that run by the event-ticket marketplace StubHub in 2006 for all of the tickets to a single event. Its single-object auction design was similar to eBay's, but the auctions all had identical hard-close ending times. ${ }^{5}$ Auctions at charity benefits are often organized similarly to StubHub's, which might explain why the final moments of so-called "silent auctions” are often anything but.

Perhaps the starkest example of an auction with future objects hidden is that described by Engelbrecht-Wiggans (1994), in which future items in an equipment auction are hidden behind a curtain until their turn for sale. The field experiment reported by Tadelis and Zettlemeyer (2011) relates to improving the disclosure of information about objects in the sequence, specifically releasing more information about automobiles’ quality condition. Some gimmicky online auction sites with very short auction durations (e.g., Bidz.com) seem to purposefully suppress information about future objects for sale. ${ }^{6}$ One could also interpret the non-sequential sort used by Google Base and eBay’s "Best Match” as obscuring information about the full set of objects for sale.

The remainder of this paper is organized as follows. Section 2 presents the model. Section 3 characterizes the equilibrium of the sequential auction with future objects revealed. Section 4 presents our three main results: on information, sequencing, and approximate efficiency. Section 5 concludes.

\footnotetext{
${ }^{4}$ We searched for event tickets and cars on eBay in June 2011. In the event tickets category (e.g., search term "U2 Tickets"), the default "Best Match" display sorted upcoming auction listings in strict order of ending time. In the automobiles category, the default "Best Match" display seemed to place little weight on auction ending time. For instance, for the search terms "Ford F150" and "Toyota Corolla", we found that in 78 percent of our searches (conducted once per day for one week), at least one of the three auctions ending soonest was not shown in the top 25 "Best Match" listings. In 42 percent of the searches, none of the three was.

${ }^{5}$ The StubHub auction's average selling price was \$50 per ticket, versus a \$148 average aftermarket value for tickets for that particular tour. Some of the StubHub auctions closed at prices as low as $\$ 3$ per ticket. Nevertheless, StubHub's CEO described the auction as a "successful experiment in true dynamic pricing." See Cohen and Grossweiner (2006).

${ }^{6}$ On Bidz.com, "auctions start at $\$ 1$ every 5 seconds!” The company has been accused of fraud and faced numerous other difficulties (Miniter, 2008).
} 


\section{Model}

The supply side of the market consists of two objects $j=1,2$ for sale. The value the seller of object $j$ derives from keeping her object is normalized to zero. The demand side of the market consists of $N \geq 3$ risk-neutral bidders with unit capacity. Each bidder $i$ 's type is described by a pair of private valuations for the two objects $\left(v_{i 1}, v_{i 2}\right)$, with the valuations independent across bidders. We will use two nested assumptions about the distribution of $\left(v_{1}, v_{2}\right)$ of each bidder:

Assumption A1: Each bidder's values $\left(v_{1}, v_{2}\right)$ follow a joint distribution $f\left(v_{1}, v_{2}\right)$ with full support on a closed and bounded rectangle $\left[L_{1}, H_{1}\right] \times\left[L_{2}, H_{2}\right] \subset \mathbf{R}_{+}^{2}$. Let $F_{j}$ be the implied marginal distribution of $v_{j}$.

Assumption A1 allows the two valuations to be arbitrarily correlated, and is sufficient for our equilibrium characterization, inefficiency bound, and for most efficiency ranking results. The stronger assumption we will occasionally resort to follows:

Assumption A2: Each bidder's valuation $v_{j}$ of object $j$ is drawn independently from a distribution $F_{j}$ with bounded density $f_{j}$ and full support on a closed interval $\left[L_{j}, H_{j}\right]$ for some $L_{j} \geq 0$.

The unit-capacity constraint makes the two objects substitutes for each bidder; the possibility that $v_{i 1} \neq v_{i 2}$ makes the objects imperfect substitutes. For instance, the objects are two different used cars, with $v_{i 1}$ indicating $i$ 's value for car 1 and $v_{i 2}$ indicating $i$ 's value for car 2 .

\section{Taxonomy of auction markets:}

We define an auction market as a set of single-object auctions. For tractability, we focus on markets that sell each object by second-price sealed-bid auction without a reserve. We classify each possible market in terms of the timing of the individual auctions, and the information available to the bidders about their private valuations of the objects: the two auctions are either sequential or separate, and information about the full set of auctions in the market is either revealed or hidden by the auctioneer. We now define and discuss these two dimensions of our taxonomy. 
In sequential auctions, all bidders participate first in auction 1, the winner (if any) exits the market, and then the remaining bidders participate in auction $2 .^{7}$ In separate auctions, each bidder chooses which one auction to participate in; bidders are not allowed / able to participate in both auctions. For instance, imagine that the auctions take place simultaneously in separate rooms.

When information is revealed, each bidder $i$ learns his valuation of both objects before he makes any bidding or entry decisions. When information is hidden, each bidder $i$ learns his value for object $j$ only at the time of its auction. Specifically: in the sequential auction, bidder $i$ learns only his first-round value before he must make his first-round bid; in the separate auctions, bidder $i$ learns his value for the one auction he enters only after he has made his entry decision.

The separated condition can be interpreted more broadly as a tractable device for modeling an auction market in which there are obstacles to participating in multiple individual auctions. The hidden condition can be interpreted more broadly as a modeling convention that captures that auction buyers know they will have future opportunities to trade but are not yet sure of the exact details of these opportunities.

\section{Bidding strategies}

Table 1 shows the equilibrium bidding strategies for each market design in the taxonomy, conditioning on bidder $i$ entering auction $j$. Not all bidders enter all auctions: in separate auctions, each bidder enters only one auction by construction. In sequential auctions, the winner of the first auction does not enter the second auction because of the unit capacity constraint. Each cell also highlights which assumption is sufficient for each result.

In all but one market design in the taxonomy, the bidding strategies are standard results: the separate auctions are isolated from each other, so bidding one's valuation is a dominant strategy (Vickrey, 1961). For the same reason, the losers of the first auction $(j=1)$ in any sequential setting bid their valuations $v_{i 2}$ in the second auction. The dominant strategy in the second stage means that we do not need to make any assumptions about information disclosure

\footnotetext{
${ }^{7}$ The assumption that the winner of auction 1 exits the market is most reasonable when disposal is costly or prohibited. For instance, the winner of a procurement auction may be prohibited from transferring the contract, and resale of a used car bought on eBay is costly due to eBay fees and other transactions costs.
} 
at the end of the first auction. ${ }^{8}$ When the auctions are organized sequentially and bidders do not know their own valuations of the second object, they share common knowledge that if they lose the first auction, they will bid their value $v_{i 2} \sim F_{2}$ in the second auction. Therefore, all bidders expect the same surplus $S=\int_{L_{2}}^{H_{2}} \int_{L_{2}}^{v_{2}}\left(v_{2}-z\right) d F_{2}^{N-2}(z) d v_{2}=\int_{L_{2}}^{H_{2}} \int_{L_{2}}^{v_{2}} F_{2}^{N-2}(z) d z d v_{2}$ should they lose the first auction. Engelbrecht-Wiggans (1994) shows that it is an iterated conditional dominant strategy equilibrium for bidder $i$ to bid her valuation $v_{i 1}$ net of this expected surplus $S$ in the first auction. The assumption of independence across objects (A2) is sufficient to make this argument go through. Under the more general assumption A1, each bidder would have a different belief about the competition in the second auction.

\begin{tabular}{|c|c|c|c|}
\hline \multirow{2}{*}{\multicolumn{2}{|c|}{ Table 1: Bidding strategies }} & \multicolumn{2}{|c|}{ Information about other auctions in the market } \\
\hline & & Hidden & Revealed \\
\hline \multirow{2}{*}{$\begin{array}{l}\text { Timing of } \\
\text { the } \\
\text { auctions }\end{array}$} & Separate & $\begin{array}{c}A 1 \Rightarrow b_{i j}=v_{i j} \\
\text { (Vickrey, 1961) }\end{array}$ & $\begin{array}{c}A 1 \Rightarrow b_{i j}=v_{i j} \\
\text { (Vickrey, 1961) }\end{array}$ \\
\hline & Sequential & $\begin{array}{c}A 2 \Rightarrow\left\{\begin{array}{l}b_{i 1}=v_{i 1}-S \\
b_{i 2}=v_{i 2}\end{array}\right. \\
\text { (Engelbrecht-Wiggans, 1994) }\end{array}$ & $\begin{array}{c}A 1 \Rightarrow\left\{\begin{array}{l}b_{i 1}=v_{i 1}-S\left(v_{i 2}, b_{i 1}\right) \\
b_{i 2}=v_{i 2}\end{array}\right. \\
(\text { New result, Theorem 1) }\end{array}$ \\
\hline
\end{tabular}

The choice-of-auction stage of the separate auction markets with information revealed raises an interesting coordination problem whereby each bidder wants to both enter an auction for which he has a high valuation, but also an auction that other bidders do not want to enter. As with any coordination game, the choice stage thus has multiple equilibria. Our efficiency ranking results below will be valid for any perfect Bayesian Nash equilibrium of the separate-auction game. Therefore, we do not explicitly analyze the equilibria of the choice-of-auction stage.

\footnotetext{
${ }^{8}$ The second-stage bidding is the same regardless of whether the bidders learn nothing, only the price, or all the bids of the first stage. This is the principal simplification relative to the first-price sealed-bid format, where disclosure of first-stage bids matters (Reiß and Schöndube 2008, Bergemann and Horner 2010).
} 


\section{Bidding in sequential auctions with information revealed}

The main technical contribution of this paper is characterizing the first-stage bidding strategy in the Sequential\&Revealed markets. ${ }^{9}$ Our analysis is under the more general assumption A1. We restrict our attention to strictly monotone symmetric pure-strategy equilibria, where "monotone" means that the first-auction bids increase in $v_{1}$ for every fixed $v_{2}$, and "strictly" rules out pooling at the same bid level for a range of different $v_{1}$ 's. As in the Sequential\&Hidden markets discussed in the previous paragraph, participation in the second stage yields a non-negative expected surplus $S$ to the losers of the first stage. The expected surplus of a first-stage loser depends obviously on her $v_{2}$ and less obviously on the winning bid in the first stage, hereafter denoted $c_{1}$. We denote this expected surplus function by $S\left(v_{2}, c_{1}\right)$. S depends on $c_{1}$ because competitors' first-stage bids depend on their respective $v_{2}$ 's, so losing the first stage to a particular $c_{1}$ contains information about the $v_{2}$ 's of the remaining competitors (who also lost to that same $c_{1}$ ). Note that this information does not impact the second-stage bidding itself, which remains dominant strategy. Instead, the information about remaining competitors enters the firststage bidding. In (Bayes-Nash) equilibrium, rational bidders bid such that they are indifferent between winning and losing at the margin, that is, between paying exactly their bid and losing to a $c_{1}$ equal to their own bid. We now formalize this intuition mathematically.

Consider any expected surplus function $S\left(v_{2}, c_{1}\right)$ and a single focal bidder who believes $c_{1}$ to be distributed according to some distribution $G_{1}$ on $\left[0, H_{1}\right]$. The focal bidder solves the following problem in the first auction:

$$
b_{1}\left(v_{1}, v_{2}\right)=\underset{\beta}{\arg \max }\left\{\int_{0}^{\beta}\left(v_{1}-c_{1}\right) d G_{1}\left(c_{1}\right)+\int_{\beta}^{\infty} S\left(v_{2}, c_{1}\right) d G_{1}\left(c_{1}\right)\right\}
$$

When the $S$ function is well behaved (i.e., when $S\left(v_{2}, L_{1}\right)=0, S$ is continuous, and $S$ does not decrease in $c_{1}$ faster than unity), the following first-order condition characterizes the best response to $S:^{10}$

\footnotetext{
${ }^{9}$ The received theory of sequential auctions for substitutes focuses either on auctions of several identical units of a good (Milgrom and Weber 2000, Black and de Meza 1992, Katzman 1999), on auctions of heterogeneous goods without information about future goods (Engelbrecht-Wiggans 1994), on the special case with only two bidders (Gale and Hausch 1994), or on vertically differentiated goods (Beggs and Graddy 1997).

${ }^{10}$ Please see the Appendix for details of why the three conditions on $S$ are sufficient for the FOC to characterize best responses. The argument is straightforward and relies on the Intermediate Value Theorem.
} 


$$
\text { FOC }: b_{1}\left(v_{1}, v_{2}\right)=\beta \text { such that } \beta=v_{1}-S\left(v_{2}, \beta\right)
$$

The best response function is intuitive given the truth-revealing property of the second-price auction: the bidder bids her value of the first object net of the opportunity cost of winning, where the opportunity cost of winning the first auction is not being able to participate in the second auction. When evaluating the option value of the second auction, the bidder assumes she loses the first stage to a competitive bid that exactly matches her first bid. This is the only situation in which changing her first bid slightly changes the outcome of the game, and $S\left(v_{2}, b_{1}\right)$ is thus the opportunity cost relevant at the margin.

In a symmetric equilibrium, $b_{1}\left(v_{1}, v_{2}\right)$ in equation (2) is the best response to all competitors also bidding according to $b_{1}\left(v_{1}, v_{2}\right)$. In other words, the expected surplus function $S$ must be correct given the first-stage bidding strategy, and vice versa. The resulting equilibrium restriction is most parsimoniously characterized with isobids - sets of bidder-value pairs that submit the same first-round bid in equilibrium:

Definition: isobid for bid-level $\boldsymbol{\beta}$ is a function $I\left(v_{2} \mid \beta\right):\left[L_{2}, H_{2}\right] \rightarrow\left[L_{1}, H_{1}\right]$ such that $b_{1}\left(I\left(v_{2} \mid \beta\right), v_{2}\right)=\beta$ for all $v_{2} \in\left[L_{2}, H_{2}\right]$.

Note that isobids of a bidding function that satisfies (2) have the following convenient form:

$$
I\left(v_{2} \mid \beta\right)=\beta+S\left(v_{2}, \beta\right)
$$

This form of the isobid leads to a useful restriction on equilibrium isobids:

Proposition 1: For every $\beta>0$, an isobid of a strictly monotone symmetric pure-strategy Bayesian Nash equilibrium must satisfy:

$$
I\left(v_{2} \mid \beta\right)=\beta+\int_{L_{2}}^{v_{2}}\left(\frac{\int_{L_{2}}^{x} \int_{L_{2}}^{I\left(w_{2} \mid \beta\right)} f\left(w_{1}, w_{2}\right) d w_{1} d w_{2}}{\int_{L_{1}}^{I\left(w_{2} \mid \beta\right)} f\left(w_{1}, w_{2}\right) d w_{1} d w_{2}}\right)^{N-2} d x
$$

We include the proof of Proposition 1 in the main body of the paper because the concept of an equilibrium isobid is central to our equilibrium and its properties. 
Proof of Proposition 1: To see the belief about second-stage competition implied by $I\left(v_{2} \mid \beta\right)$, consider a bidder who bids $\beta$ in the first stage. If he loses, he will face $N$-2 other bidders who bid less than $\beta$ in the first stage. In a strictly monotone equilibrium, bidding less than $\beta$ in the first stage means $v_{1}<I\left(v_{2} \mid \beta\right)$; that is, the surviving competitors have $\left(v_{1}, v_{2}\right)$ below the $I\left(v_{2} \mid \beta\right)$ isobid. The focal bidder's belief that one of the competitors' $v_{2}$ is below some "competitive level" magnitude $c_{2}$ is thus captured by a distribution $F_{2}\left(c_{2} \mid \beta\right)$ defined by the ratio of the $f$ probability mass below $I\left(v_{2} \mid c_{1}\right)$ and to the left of $c_{2}$, and the entire $f$ probability mass under the isobid $I\left(v_{2} \mid c_{1}\right)$ :

$$
F_{2}\left(c_{2} \mid \beta\right)=\frac{\int_{L_{2}}^{c_{2}} \int_{L_{1}}^{I\left(w_{2} \mid \beta\right)} f\left(w_{1}, w_{2}\right) d w_{1} d w_{2}}{\int_{L_{2}}^{H_{2} I\left(w_{2} \mid \beta\right)} \int_{L_{1}}} \stackrel{(F i g 1)}{=} \frac{\int_{X} f(w) d w}{\int_{X+Y} f(w) d w},
$$

where $\mathrm{X}$ and $\mathrm{Y}$ are the pertinent areas under the isobid illustrated in Figure 1.

Given $F_{2}\left(c_{2} \mid \beta\right)$ and independence across bidders, the expected surplus implied by facing $N-2$ competitors under $I\left(v_{2} \mid \beta\right)$ is the integrated probability of winning the second auction—a standard result in auction theory:

$$
S\left(v_{2}, \beta\right)=\int_{L_{2}}^{v_{2}}\left(v_{2}-c_{2}\right) d F_{2}^{N-2}\left(c_{2} \mid \beta\right)=\int_{L_{2}}^{v_{2}} F_{2}^{N-2}\left(c_{2} \mid \beta\right) d c_{2} \quad,
$$

where the second equality follows from integration by parts. Plugging equation (5) into equation (6) yields the expected surplus $S$ implied by $I\left(v_{2} \mid \beta\right)$, and plugging this $S$ into equation (3) yields the equilibrium condition (4), ensuring that the belief about second-stage competition implied by $I\left(v_{2} \mid \beta\right)$ is correct. QED Proposition 1.

The intuition for Proposition 1 is that the isobid for bid-level $\beta$ implies a belief about secondstage competition, which in turn implies the isobid via $I\left(v_{2} \mid \beta\right)=\beta+S\left(v_{2}, \beta\right)$. In Bayes-Nash equilibrium, this belief must be correct. Considering isobids instead of directly solving for the bidding function involves a useful dimension reduction: equation (4) shows that an isobid for 
each bid level depends only on itself and not on the isobids for any other bid levels. This dimension reduction follows from thinking at the margin: each bidder needs to consider only those other bidders that bid exactly the same amount on the first object.

\section{Figure 1: Illustration of an isobid}

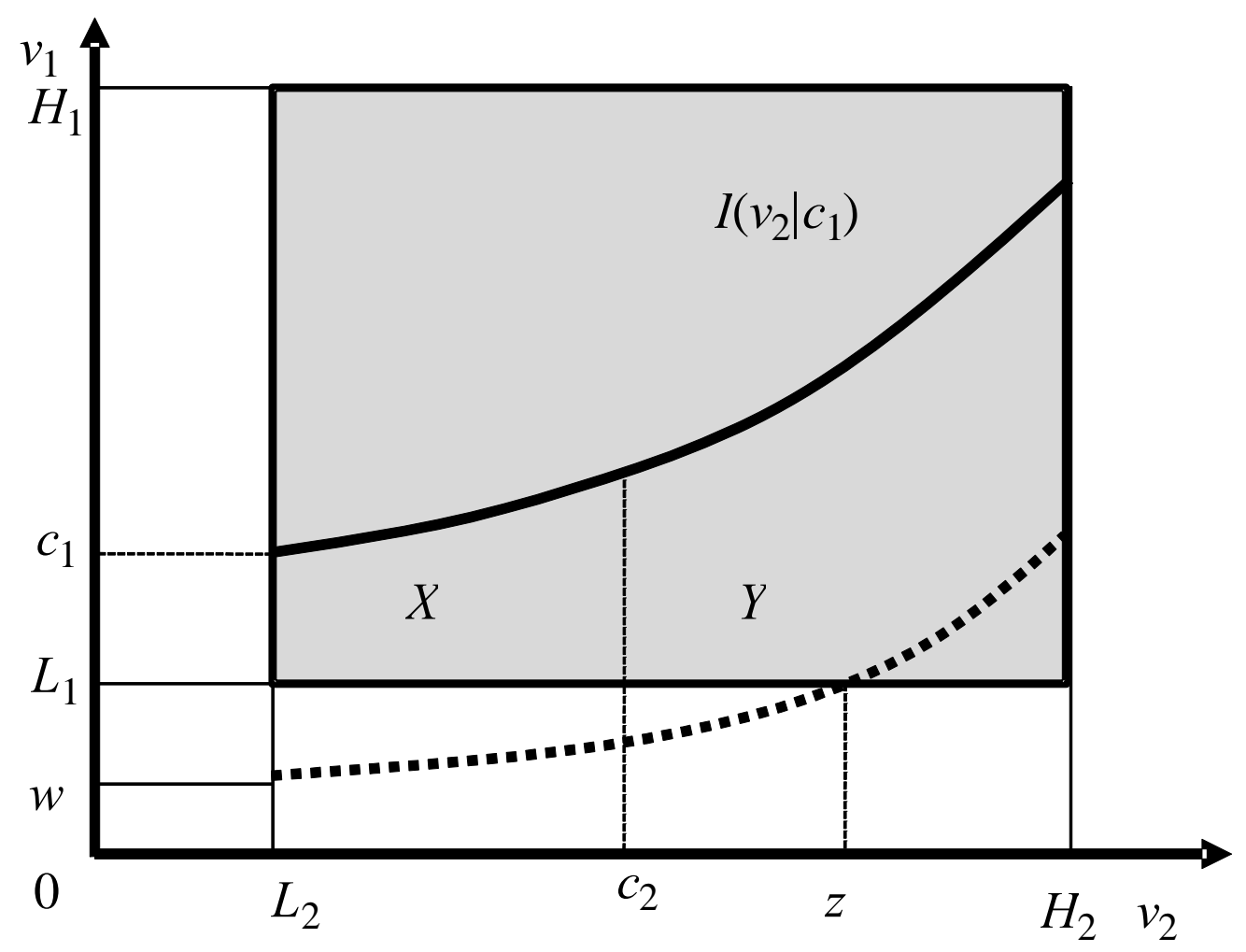

Note to Figure: This figure serves two purposes: first, the solid line illustrates a valid isobid $I\left(v_{2} \mid c_{1}\right)$. Second, the dashed line shows a curve that cannot be an isobid for bid-level $w$. Please see the text for more details.

Proposition 1 implies a surprising property of any strictly monotone equilibrium, namely, that $b_{1}\left(v_{1}, v_{2}\right) \geq L_{1}$ almost surely. Bids below $L_{1}$ are ruled out because the dashed line in Figure 1 cannot satisfy the equilibrium condition: consider the bidder $\left(L_{1}, z\right)$ at the intersection of the dashed isobid curve of some bid-level $w<L_{1}$ and the lower boundary of the valuation support: at the margin (under the curve), she is guaranteed to lose the second auction by encountering only stronger competitors, so her best response to the dashed curve is to not shade her first-stage bid below her valuation $v_{1}=L_{1}$, which is a higher first-stage bid level than the bid-level 
corresponding to the dashed curve. Symmetric pure-strategy equilibrium considerations alone thus restrict attention to first-round bids at or above the lower bound of the support of $v_{1}$.

To close the symmetric equilibrium construction, we need to show that the isobids defined by Proposition 1 exist and imply a well-behaved (continuous, $S\left(v_{2}, L_{1}\right)=0$, and not decreasing in $c_{1}$ faster than unity) expected surplus function $S\left(v_{2}, c_{1}\right)=I\left(v_{2} \mid c_{1}\right)-c_{1}$. This is our main technical result:

Theorem 1: For any joint distribution $f\left(v_{1}, v_{2}\right)$ that satisfies A1, there is a unique strictly monotone symmetric pure-strategy Bayes-Nash equilibrium with a continuous bidding function $b_{1}\left(v_{1}, v_{2}\right)$ that satisfies:

- $\quad b_{1}\left(L_{1}, v_{2}\right)=L_{1}, b_{1}\left(v_{1}, L_{2}\right)=v_{1}$ and $v_{1}>b_{1}\left(v_{1}, v_{2}\right)>L_{1}$ for all $\left(v_{1}, v_{2}\right)>\left(L_{1}, L_{2}\right)$,

- $\quad b_{1}\left(v_{1}, v_{2}\right)$ is decreasing in $v_{2}$ for all $\left(v_{1}, v_{2}\right)>\left(L_{1}, L_{2}\right)$

The equilibrium can be characterized by a unique set of equilibrium isobids $I\left(v_{2} \mid \beta\right)$, each of which satisfies equation (4). The isobids imply a unique expected surplus function $S\left(v_{2}, c_{1}\right)=I\left(v_{2} \mid c_{1}\right)-c_{1}$, which is continuous, approaches zero as $c_{1}$ approaches $L_{1}$, and does not decrease in $c_{1}$ faster than unity. In terms of $S$, the bidding function $b_{1}\left(v_{1}, v_{2}\right)$ satisfies $b_{1}\left(v_{1}, v_{2}\right)=v_{1}-S\left(v_{2}, b_{1}\left(v_{1}, v_{2}\right)\right)$.

We construct the equilibrium in three steps: First, the full support and boundedness of $f$ imply that for every $\beta \in\left(L_{1}, H_{1}\right]$, a unique function $I$ exists that satisfies equation (4). This function is a candidate for an isobid curve $I\left(v_{2} \mid \beta\right)$. Second, we show that the candidate surplus function $S\left(v_{2}, c_{1}\right)=I\left(v_{2} \mid c_{1}\right)-c_{1}$ implied by the candidate isobids is well behaved: $S\left(v_{2}, L_{1}\right)=0$ , $S$ is continuous, and $S$ does not decrease in $c_{1}$ faster than unity. Third, we note that equation (2) characterizes the best response to a well-behaved $S$ and the resulting bidding function is increasing in $v_{1}$, so the candidate isobids are indeed the equilibrium isobids.

The most notable property of the equilibrium is that all bidders bid at least $L_{1}$, regardless of their $v_{2}$. In other words, the equilibrium second-stage surplus vanishes as the bid-level $c_{1}$ approaches the lower bound of the support $L_{1}$, even when the $v_{2}$ is large relative to the 
competition, for example, when $v_{2}=H_{2}$. The $L_{1}$ isobid is thus a constant function $I\left(v_{2} \mid L_{1}\right)=L_{1}$. From the perspective of the bidders, an $L_{1}$ candidate isobid $I\left(v_{2} \mid L_{1}\right)$ with a positive mass underneath unravels as follows. Suppose a bidder $\left(v_{1}, v_{2}\right)$ with $v_{1}>L_{1}$ is on the $I\left(v_{2} \mid L_{1}\right)$ isobid line. In conjecturing a positive expected surplus should she lose, the bidder is relying on other bidders $\left(\tilde{v}_{1}, \tilde{v}_{2}\right)$ with smaller but still non-minimum valuations $L_{i}<\tilde{v}_{i}<v_{i}$ to also bid $L_{1}\left(L_{i}<\tilde{v}_{i}\right.$ is critical for a positive mass of such competitors). In a symmetric equilibrium, those bidders $\left(\tilde{v}_{1}, \tilde{v}_{2}\right)$ rely on other bidders with yet smaller but still non-minimum valuations to also bid $L_{1}$, all the way down to bidders arbitrarily near the point $\left(L_{1}, L_{2}\right)$. But bidders on $I\left(v_{2} \mid L_{1}\right)$ sufficiently close to $\left(L_{1}, L_{2}\right)$ realize they will lose the second auction almost surely because the probability mass under $I\left(v_{2} \mid L_{1}\right)$ and left of a small $v_{2}$ is zero (since an equilibrium $I$ must have a slope and curvature of zero at $\left.L_{2}\right)$. Therefore, the cascade unravels, the $\left(\tilde{v}_{1}, \tilde{v}_{2}\right) \approx\left(L_{1}, L_{2}\right)$ competitors bid a small amount strictly greater than $L_{1}$, and the focal bidder $\left(v_{1}, v_{2}\right)$ thus also bids strictly more than $L_{1}$. This unraveling corrects for the loser's curse that would result from bidding $L_{1}$.

One way to understand the bidding incentives is to think of the first auction as an auction with a common value component arising from the fact that the opportunity cost of winning the first auction depends on the types of the other bidders. Since losing to a lower bid today makes higher competition tomorrow more likely, the common value component implies a "loser's curse" (Holt and Sherman 1994, Pesendorfer and Swinkels 1997) in that a failure to anticipate the informational content of winning makes one bid too low. Specifically, ignoring the information about tomorrow's competition contained in losing to a very low bid today would make some bidders bid very low, only to be surprised tomorrow at the intensity of competition.

The first step of the proof (existence and uniqueness of candidate isobids) relies on showing that a $K$-times repetition of the mapping on the space of functions defined by the RHS of equation (4) is a contraction mapping, so there is a natural numerical method for computing isobids: 
Corollary to Theorem 1 (numerical procedure for computing $b_{1}\left(v_{1}, v_{2}\right)$ ):

The following steps can be used to numerically approximate $b_{1}\left(v_{1}, v_{2}\right)$ on a grid:

1) Starting with $c_{1}=H_{1}$ and proceeding in small steps of size $\delta$, compute the equilibrium $I\left(v_{2} \mid c_{1}\right)$ for a set of $c_{1} \in\left\{L_{1}, L_{1}+\delta, L_{1}+2 \delta, \ldots, H_{1}\right\}$ by iterating equation (4), starting with $I\left(v_{2} \mid c_{1}+\delta\right)$.

2) Construct equilibrium $S\left(v_{2}, c_{1}\right)$ by subtracting $c_{1}$ from $I\left(v_{2} \mid c_{1}\right)$.

3) Solve for $b_{1}\left(v_{1}, v_{2}\right)$ approximately on a grid using equation (2).

The first step makes use of continuity of $I$ in $c_{1}$ to initialize each set of iterations. Starting with $c_{1}=H_{1}$ is efficient because isobids for high values of $c_{1}$ have greater mass of $f$ underneath, so their mapping contracts faster (see proof of Step 1 of Theorem 1).

\section{Example: Three bidders, $\boldsymbol{f}$ uniform on $[0,1] \times[0, K]$}

When $f$ is a uniform distribution on a rectangle and there are only three bidders, the equilibrium condition (4) yields an analytical solution for the equilibrium isobids because the condition implies a tractable differential-integral equation. The uniform distribution simplifies the integral under an isobid to $\int_{0}^{I\left(v_{2} \mid q_{1}\right)} f\left(v_{1}, v_{2}\right) d v_{1}=\frac{\min \left[I\left(v_{2} \mid c_{1}\right), 1\right]}{K}$. Three bidders simplify the equilibrium condition because the crucial exponent is $N-2=1{ }^{11}$ In the Appendix, we show that these simplifications imply that the equilibrium isobids are $I\left(v_{2} \mid c_{1}\right)=c_{1} \cosh \left[A\left(c_{1}\right) v_{2}\right]$, where the function $A\left(c_{1}\right)$ satisfies $1=c_{1} A\left(c_{1}\right) \sinh \left(K A\left(c_{1}\right)\right)$ for $c_{1}$ low-enough that $I\left(K \mid c_{1}\right)<1$, and satisfies $K A\left(c_{1}\right)-\frac{1}{A\left(c_{1}\right)}=\log \left(1+\sqrt{1-c_{1}^{2}}\right)-\log \left(c_{1}\right)-\sqrt{1-c_{1}^{2}}$ for higher $c_{1}$. The two cases are necessary to capture the fact that isobids of low bid levels do not reach the upper bound of $v_{1}$ even for the highest possible $v_{2}$. With $K=1$, the cutoff is $c_{1}=0.552$, and it is easy to show that increasing $K$ reduces the cutoff.

\footnotetext{
${ }^{11}$ The differential-equation approach for solving for the isobids analytically is complicated for $N>3$. Extending the approach used in the $N=3$ example would require solving a differential equation of the $(N-1)$ st order.
} 
Figure 2 shows representative bidding functions for $K=\{1,2,3)$ at four levels of $\mathrm{v}_{1}(0.1,0.4$ 0.7 , and 1$)$. For a given $\left(v_{1}, v_{2}\right)$, higher $K$ implies a higher equilibrium bid because there are more remaining competitors with higher $v_{2}$ 's and hence less surplus. However, it is also clear from Figure 2 that higher $K$ involves higher expected surplus for the $\left(v_{1}, K\right)$ bidder, so the secondround competition is actually relatively weaker with higher $K$. It can be shown that the relative ordering is true for all $v_{2}$ 's, namely that $b_{1}\left(v_{1}, v_{2} / K\right)$ decreases in $K$. However, note that every $\left(v_{1}, K\right)$ bidder still submits a positive first-round bid.

Figure 2: Bidding function in the Uniform $[0,1] \times[0, K]$ example

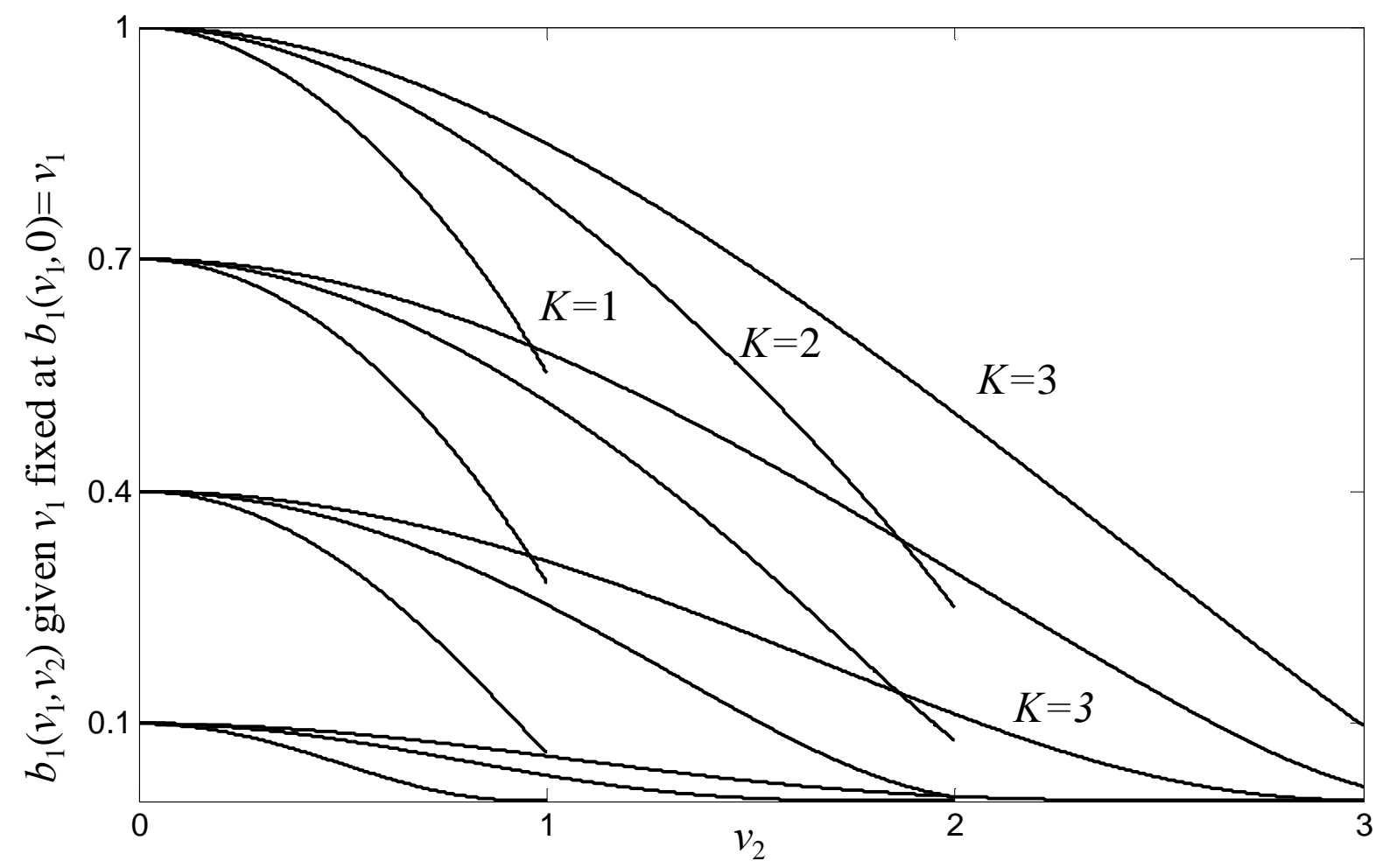

Note to Figure: Each solid line shows how $b_{1}\left(v_{1}, v_{2}\right)$ decreases as $v_{2}$ increases and $v_{1}$ remains fixed at $v_{1}=b_{1}\left(v_{1}, 0\right)$ for four levels of $v_{1}$ and three values of $K$. The $v_{1}=0.1$ bids asymptote toward zero as $v_{2}$ approaches $K$. 


\section{Efficiency bounds and rankings}

Having characterized the equilibrium bidding in a Sequential\&Revealed market, we now turn to results about its efficiency. We present two sets of results: First, we show that the Sequential\&Revealed market generates greater expected surplus than any other market format in our taxonomy. Second, we show that the Sequential\&Revealed market in a certain sense approximates full efficiency. Both sets of results rely on our workhorse finding that the Sequential\&Revealed market is more efficient than the greedy allocation, defined as follows:

Definition: The greedy allocation assigns the first object to the bidder with the highest $v_{1}$, and assigns the second object to the bidder with the highest $v_{2}$ among the remaining bidders.

Theorem 2: Under the distributional assumption $\mathrm{A} 1$ and for any number of bidders $N \geq 3$, the unique monotone symmetric pure-strategy Bayes-Nash equilibrium of the sequential auction with future objects revealed generates greater expected social surplus than the greedy allocation.

Proof of Theorem 2: Let $A$ be the bidder with the highest $v_{1}, B$ be the bidder with the highest $b_{1}\left(v_{1}, v_{2}\right)$, and let $z$ be the maximum $v_{2}$ among all bidders other than $A$ and $B$. Note that $z$ is the maximum of $N-2$ bidders with $\left(v_{1}, v_{2}\right)$ under the $I\left(v_{2} \mid b_{B, 1}\right)$ isobid, that is, exactly the competition bidder $B$ expects at the margin. In terms of our notation, $z=c_{2}$ in equation (6) with $\beta=b_{1}\left(v_{B 1}, v_{B 2}\right)$.

When $A=B$, the two allocations are the same. When $A \neq B$, the greedy allocation generates social surplus of $W_{\text {greedy }}=v_{A, 1}+\max \left(z, v_{B, 2}\right)$. In contrast, the sequential auction with information revealed generates $W_{\text {rev }}=v_{B, 1}+\max \left(z, v_{A, 2}\right)$.

We show that for every realization of $\left(v_{A, 1}, v_{A, 2}\right)$ and $\left(v_{B, 1}, v_{B, 2}\right), E_{z}\left(W_{\text {rev }}\right)>E_{z}\left(W_{\text {greedy }}\right)$. Subtracting $z$ from both surpluses, the crucial difference is

$$
W_{\text {rev }}-W_{\text {greedy }}=\underbrace{v_{B, 1}-v_{A, 1}}_{\begin{array}{c}
\text { efficiency loss in } \\
\text { the 1st auction }
\end{array}}+\underbrace{\max \left(0, v_{A, 2}-z\right)-\max \left(0, v_{B, 2}-z\right)}_{\begin{array}{c}
\text { efficiency gain in } \\
\text { the 2nd auction }
\end{array}}
$$

The greedy allocation always realizes more surplus in the first auction. However, the revealedinfo auction realizes more surplus in the second auction as long as $v_{A, 2}>v_{B, 2}$, which is necessary 
for $b_{A, 1}<b_{B, 1}$ and $v_{A, 1}>v_{B, 1}(A \neq B)$. Since $z$ is the maximum of $N$-2 bidders with $\left(v_{1}, v_{2}\right)$ under the $I_{B}$ isobid, taking an expectation over $z$ yields $E_{z}[\max (0, x-z)]=S\left(x, b_{B, 1}\right)$, where $S$ is the equilibrium expected surplus function characterized by Theorem 1 . Therefore, the expectation of the difference between surpluses is the (always-positive) difference between the isobids at $v_{A, 2}$ :

$$
E_{z}\left(W_{\text {rev }}\right)-E_{z}\left(W_{\text {greedy }}\right)=\underbrace{v_{B, 1}-v_{A, 1}}_{\begin{array}{c}
\text { efficiency loss in } \\
\text { the 1st auction }
\end{array}}+\underbrace{S\left(v_{A, 2}, b_{B, 1}\right)-S\left(v_{B, 2}, b_{B, 1}\right)}_{\begin{array}{c}
\text { expected efficiency } \\
\text { gain in the 2nd auction }
\end{array}}=I\left(v_{A, 2} \mid b_{B, 1}\right)-I\left(v_{A, 2} \mid b_{A, 1}\right)>0
$$

where the last equality follows from the definition of an isobid: $v_{B, 1}=b_{B, 1}+S\left(v_{A, 2}, b_{B, 1}\right)$. Please see Figure (3) for a graphical illustration of this proof. QED Theorem 2.

Figure 3: Illustration of Theorem 2: Sequential auction with information about future objects revealed is more efficient than the greedy allocation

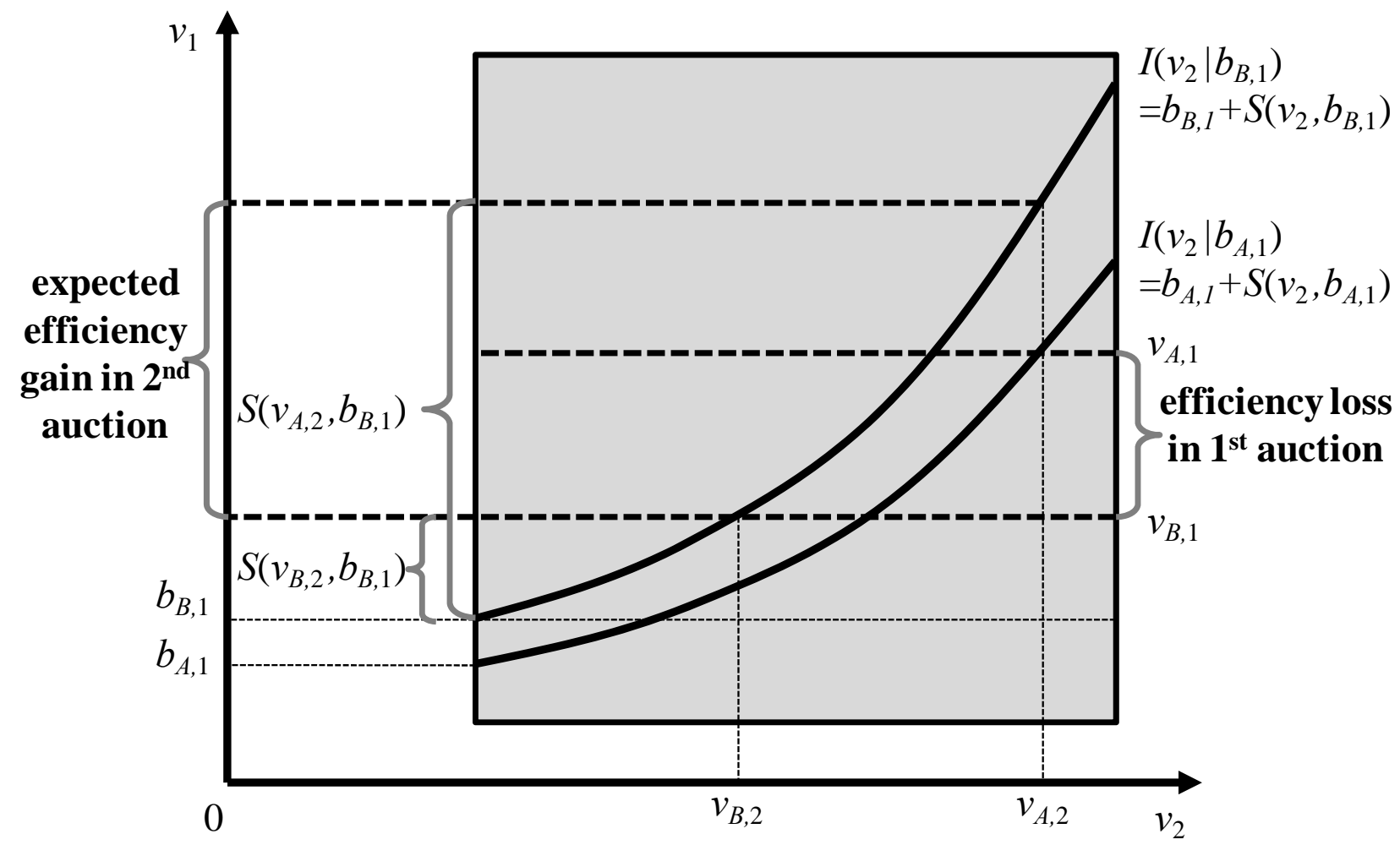

Recall that the greedy allocation first sorts the bidders according to their valuations of the first object, so the first auction in the sequence generates the maximum possible social surplus under the greedy allocation. The intuition for Theorem 2 is that whenever the sequential auction with 
information revealed changes the identity of the first-auction winner (and thus results in a loss in efficiency due to a lower $v_{1}$ of the new winner), the second period more than compensates in expectation: the person who would have received the second object under the greedy allocation must have such a high $v_{2}$ that his presence in the second auction increases expected social surplus. Note, however, that the efficiency comparison does not hold in realization: there always exist profiles of bidders types for which the greedy allocation is efficient whereas the sequential auction with future objects revealed is not (we provide an example of an inefficient realization as part of the overall discussion of our efficiency ranking below).

When each bidder's valuations are independent across the two auctions, the Sequential\&Hidden auction market results in the greedy allocation. We thus have the following corollary to Theorem 2:

Corollary to Theorem 2: Under the distributional assumption A2 and for any number of bidders $N \geq 3$, revealing information about future objects increases the expected efficiency of sequential-auction markets.

Theorem 2 implies that the efficiency comparison between Sequential\&Revealed generalizes at least to any environment in which Sequential\&Hidden is greedy in equilibrium, and we conjecture that it generalizes to environment A1. However, we are unable to characterize bidding behavior in the Sequential\&Hidden auction in environments beyond A2. The issue is that when there is correlation between $v_{1}$ and $v_{2}$, information about $v_{2}$ is, in a sense, only partially hidden: bidders with different $v_{1}$ 's will have different beliefs about their $v_{2}$ 's. Bidders must condition their first-round bids on their beliefs about their own $v_{2}$ 's and also on their beliefs at the margin about others' beliefs. Thus the elegant analysis of Engelbrecht-Wiggans (1994) no longer goes through, and whether the bidder with the highest $v_{1}$ will actually submit the highest first-auction bid is unclear. Our next result indicates that sequencing itself enhances efficiency:

Theorem 3: Under the distributional assumption A1 and in a market with information revealed, the unique monotone symmetric pure-strategy Bayes-Nash equilibrium of the Sequential Auction generates greater expected social surplus than does any Perfect Bayesian Nash Equilibrium of the Separate Auctions. 
Proof of Theorem 3: As in the Proof of Theorem 2, let $B$ be the bidder with the highest $b_{1}\left(v_{1}, v_{2}\right)$. There are two cases, depending on realized entry into the first auction.

\section{Case 1: At least one bidder enters auction 1}

If $B$ also wins the first object when the auctions are separated then the separate auctions generate weakly less social surplus because the set of participants in the separated second auction is a subset of the participants in a second auction in a sequence. Since the highest- $v_{2}$ participating bidder wins the second object in either equilibrium, separating the second auction must therefore generate weakly less social surplus.

Now assume $B$ does not win the first auction when the auctions are separated. Let $A$ be the bidder who wins auction 1 , and let $z$ be the maximum $v_{2}$ among all bidders other than $A$ and $B$. As in the Proof of Theorem 2, the expected social surplus with the auctions sequenced is $E_{z}\left(W_{\text {seq }}\right)=v_{B, 1}+S_{B}\left(v_{A, 2}\right)+E(z)$. The expected social surplus with the auctions separated is bounded by assuming that all bidders other than $A$ enter the second auction: $E_{z}\left(W_{\text {sep }}\right) \leq$ Bound $\left(E W_{\text {sep }}\right) \equiv v_{A, 1}+E_{z}\left[\max \left(0, v_{B, 2}-z\right)\right]+E(z)$. We have shown in the Proof of Theorem 2 that $E_{z}\left(W_{\text {seq }}\right)>$ Bound $\left(E W_{\text {sep }}\right)$.

Case 2: No bidders enter auction 1

With all bidders in auction 2, the social surplus is the highest $v_{2}$ from all $N$ bidders. Let $C$ be the bidder with highest $v_{2}$ other than $v_{B, 2}$. With the auctions sequenced, the social surplus is $W_{\text {seq }}=v_{B, 1}+v_{C, 2}$, whereas the separate auctions yield $W_{\text {sep }}=\max \left(v_{C, 2}, v_{B, 2}\right)$ in the present case. We show that conditional on any $\left(v_{B, 1}, v_{B, 2}\right), E_{C}\left(W_{\text {seq }}\right)>E_{C}\left(W_{\text {sep }}\right)$.

Let $F_{B, 2}(x)$ be the $c d f$ of a $v_{2}$ drawn randomly from below the $B$ isobid. Therefore, $\operatorname{Pr}\left(v_{C, 2}<x\right)=F_{B, 2}^{N-1}(x)$. The difference between the two expected social surpluses is

$$
\begin{gathered}
E_{C}\left(W_{\text {seq }}\right)-E_{C}\left(W_{\text {sep }}\right)=\operatorname{Pr}\left(v_{C, 2}<v_{B, 2}\right)\left[v_{B, 1}-E_{C}\left(v_{B, 2}-v_{C, 2} \mid v_{C, 2}<v_{B, 2}\right)\right]+\left[1-\operatorname{Pr}\left(v_{C, 2}<v_{B, 2}\right)\right] v_{B, 1}= \\
=v_{B, 1}-\underbrace{\int_{B, 2}^{v_{L_{2}}}\left(v_{B, 2}-x\right) d F_{B, 2}^{N-1}(x)}_{\text {pseudo-surplus } \tilde{S}\left(v_{B, 2}\right)}>v_{B, 1}-\underbrace{\int_{L_{B}}^{v_{2}}\left(v_{B, 2}-x\right) d F_{B, 2}^{N-2}(x)}_{\text {equilibrium surplus } S\left(v_{B, 2}\right)}=b_{B, 1} \geq L_{1} \geq 0
\end{gathered}
$$


The first equality sign follows from the two relative orderings of $v_{B, 2}$ and $v_{C, 2}$ : when $v_{B, 2} \leq v_{C, 2}$, society is better off by $v_{B, 1}$. When, on the other hand, $v_{B, 2}>v_{C, 2}$, the social surplus difference has an ambiguous sign and amounts to $v_{B, 1}-E_{C}\left(v_{B, 2}-v_{C, 2} \mid v_{C, 2}<v_{B, 2}\right)$. The second equality sign highlights that the average $W_{\text {seq }}-W_{\text {sep }}$ across the two orderings amounts to $v_{B, 1}$ minus the difference between $v_{B, 2}$ and $v_{C, 2}$ whenever $v_{B, 2}>v_{C, 2}$. The critical insight is that this difference is of the same form as the equilibrium bidding function in equation (2), except the "expected surplus” part (the integral) considers $N$-1 rather than $N$-2 opponents (see equation 6). Since more opponents imply smaller surplus, the first inequality follows, so the expected $W_{\text {seq }}-W_{\text {sep }}$ difference exceeds the $B$ 's first-auction bid. Therefore, $E_{C}\left(W_{\text {seq }}\right)>E_{C}\left(W_{\text {sep }}\right)$. QED Theorem 3.

Together with the trivial observation (under assumption A2) that sequencing increases efficiency when information is hidden, Theorems 2 and 3 indicate that the sequential auction with future objects revealed is the most efficient auction market in our taxonomy:

Summary of efficiency rankings within the taxonomy: Under the distributional assumption A2 and for any number of bidders $N \geq 3$, the Sequential\&Revealed auction market generates greater expected social surplus than any other auction market in the taxonomy

Of course, the sequential auction with future objects revealed is not fully efficient. With three bidders and $f$ Uniform of the unit square, the worst-case efficiency loss occurs when the bidder values are about $(1,0.99),(0,1)$, and $(0.58,0)$ : the first bidder just loses the first auction to the last bidder, resulting in 0.42 of squandered social surplus. Full efficiency in our setting requires a multi-object auction design, such as the Vickrey-Clarke-Groves auction. Our next result shows, however, that although VCG avoids the worst-case scenario, the expected efficiency gain of switching from the sequential auction design to the VCG is in a certain sense small:

Theorem 4: Under the distributional assumption A2 and for any number of bidders $N \geq 3$,

- The inefficiency of the Sequential\&Revealed market is bounded above by the difference in expected social surplus between an $N$ bidder auction and an $N-1$ bidder auction for the second object held in isolation. 
- The Sequential\&Revealed market with $N+1$ bidders generates greater expected surplus than does the efficient Vickrey-Clarke-Groves mechanism with $N$ bidders.

Proof of Theorem 4: Let $V_{j}^{(k: n)}$ denote the random variable given by the $k$-th highest of $n$ draws from $F_{j}$. Let $W_{V C G}^{N}$ denote the expected social surplus in the VCG mechanism with $N$ bidders. $W_{V C G}^{N}$ is bounded above by the expected social surplus in an economy without the unit-capacity constraint, in which each object is allocated to the bidder who values it the most: $W_{V C G}^{N}<E\left(V_{1}^{(1: N)}\right)+E\left(V_{2}^{(1: N)}\right)$.

Now let $W_{\text {seq\&rev }}^{n}$ denote the expected social surplus in a sequential auction with information revealed and $n$ bidders. Theorem 2 implies that $W_{\text {seq \& rev }}^{n}$ is bounded below by the greedy allocation that awards the first object to the bidder who values it the most, but then excludes that bidder from the second auction. Under assumption A2, the greedy expected surplus is: $W_{\text {greedy }}^{n}=E\left(V_{1}^{(1: n)}\right)+E\left(V_{2}^{(1: n-1)}\right)$. Therefore, $W_{\text {seq \&rev }}^{n}>E\left(V_{1}^{(1: n)}\right)+E\left(V_{2}^{(1: n-1)}\right)$. Combining the above two bounds with $n=N$ yields $W_{V C G}^{N}-W_{\text {seq \& } r_{r e v}^{N}}<E\left(V_{2}^{(1: N)}\right)-E\left(V_{2}^{(1: N-1)}\right)$. Combining the above two bounds with $n=N+1$ yields $W_{\text {seq\&rev }}^{N+1}-W_{V C G}^{N}>E\left(V_{1}^{(1: N+1)}\right)-E\left(V_{1}^{(1: N)}\right)>0 . Q E D$ Thm 4 .

The first part of Theorem 4 says that the inefficiency of the entire two-auction sequence is less than the efficiency loss in the second auction, held in isolation, if $N-1$ rather than $N$ bidders participated in it. This bound becomes tighter as the population variance in $v_{2}$ decreases and/or as $N$ increases. Intuitively, the less expected bidder surplus the second auction provides, the more efficient is the sequential auction with information revealed. The second part of Theorem 4 says that a designer concerned about efficiency would rather hold the sequential auction with information revealed than use VCG if the former attracts just a single additional bidder-for example, due to its comparative simplicity. This bound is in the spirit of Bulow and Klemperer (1996), who show in the single-object setting that the revenue benefit of an optimally chosen reserve price is smaller than the revenue benefit of adding one more bidder to the game.

At present we have not been able to generalize Theorem 4 to setting A1. The issue is that when values are correlated we cannot exploit the simple characterization of the greedy expected surplus as $W_{\text {greedy }}^{n}=E\left(V_{1}^{(1: n)}\right)+E\left(V_{2}^{(1: n-1)}\right)$. Instead, the best bound on the greedy surplus is 
$W_{\text {greedy }}^{n} \geq E\left(V_{1}^{(1: n)}\right)+E\left(V_{2}^{(2: n)}\right)$, so the present proof technique for Theorem 4 delivers a weaker inefficiency bound. Specifically, inefficiency is bounded by the expected difference between the top two valuations of the second object among $N$ bidders.

Simulation results in Budish (2008) suggest that the inefficiency of the sequential auction with future-objects revealed is often substantially smaller than the Theorem 4 bound. For instance, if there are three bidders with values for each object distributed uniformly on $[0,1]$ then VCG achieves expected social surplus of 1.45 , whereas the sequential auction with future objects revealed achieves expected social surplus of 1.44 .

\section{Conclusion}

This paper studies how single-object auctions "aggregate up" into a multi-object auction market. Such markets are especially prevalent in settings where there would be large coordination or complexity costs associated with adopting a fully efficient multi-object auction-for example, the costs of coordinating multiple different sellers on eBay or at Sotheby's. We identify two aspects of such auction-market design that unambiguously increase expected marketplace efficiency in our model: First, the individual auctions should be conducted in a sequence; Second, the auctioneer should reveal to the bidders in advance all information about the objects being auctioned. Besides demonstrating that the sequential auction with future objects revealed is more efficient than its alternatives, we also show that its expected efficiency is close to the efficient social surplus. Specifically, the market designer would rather run the sequential auction with future objects revealed than run a fully efficient mechanism but lose one bidder. Together, our results help explain the prevalence of the sequential auction with future objects revealed in practice.

The efficiency ranking results validate the standard government practice of sequencing procurement auctions and announcing upcoming contracts far in advance (Jofre-Bonet and Pesendorfer 2003). Designers of private trading platforms concerned with efficiency should also strive to sequence their auctions and enable all bidders to participate in the full sequence. For example, eBay should reintroduce its "Bid Assistant" tool that allowed a bidder to program a proxy agent to bid in a sequence of auctions. ${ }^{12}$ The wholesale car auctioneer Tadelis and

\footnotetext{
${ }^{12}$ See http://www2.ebay.com/aw/core/200809051050532.html regarding eBay’s removal of Bid Assistant.
} 
Zettlemeyer (2011) describe should consider reducing the number of separate auction lanes and use technology to both speed up each auction and facilitate participation across lanes. An example of a market using technology to sequence individual auctions is the Suwon wholesale car market in Korea, which sells up to 1,000 cars per day (Kim and Lee 2009). At Suwon, each car is presented on a large screen of a single auction hall and sold by an ascending button auction facilitated by modern electronic displays and communications equipment. An ultimate role model of sequencing may be the Aalsmeer wholesale flower auction in the Netherlands, which sells up to 60,000 lots of flowers every day in just five auction halls separated by flower type (Kambil and van Heck 1998). Each hall has several clocks that take turns running auctions, with each auction lasting about four seconds. Altogether, there are therefore only five separate sequences of auctions at Aalsmeer.

Designers of private marketplaces should also strive to provide information about objects sold in future auctions. Many real-world markets already do this well: the traditional auction houses, such as Sotheby's and Christie's, publish auction catalogs and allow inspection of their merchandise before each auction sequence begins. The aforementioned Aalsmeer flower auction utilizes communications technology to enable bidders to participate in auctions in distinct halls and see upcoming lots. On eBay, sellers list upcoming auction-endings several days in advance, so bidders can see the pipeline and bid accordingly (Zeithammer, 2006). However, the upcoming listings are not easy to find under the new "Best Match" default ordering. The cost of search for online auctions may seem small, but Haruvy and Popkowski-Lesczyc (2010) find substantial price dispersion between identical listings and little evidence of rational search behavior. Therefore, our results suggest that eBay should go back to ordering its auctions by "Ending Soonest” and perhaps work even harder to find alternative auctions for bidders to participate in.

To assess the impact of sequencing and information on efficiency, we extended the auction literature by characterizing the first-stage bidding in the sequential auction with future objects revealed. We show that for any distribution with a density and full support on a compact rectangle, there always exists a unique strictly monotone pure-strategy equilibrium with mostly intuitive properties: bidders bid their private values of today's object minus the expected surplus of tomorrow's auction, where the expected surplus function increases convexly in the valuation of tomorrow's unit and, less obviously, depends on the valuation of today's unit. The main counterintuitive property of the equilibrium is that all bidders bid somewhat aggressively in the 
first stage; specifically, they bid at least the lower bound of the support of the first-object valuations. In the equilibrium, losing to a very small bid implies very strong second-round competition; rational bidders correct for this "loser's curse.”

A limitation of our analysis is that it focuses on the case of just two auctions and a fixed set of bidders. It would be desirable to allow for a longer (perhaps infinite) sequence of auctions, and to allow bidders to arrive and depart from the market at different times. Unfortunately, such analysis quickly becomes intractable due to the asymmetry and learning issues first raised in the seminal paper of Milgrom and Weber (2000); ${ }^{13}$ as is clear from our characterization in Section 3, even the case of two auctions and a fixed set of bidders is quite involved. Our intuition is that our efficiency results would be robust to longer sequences, but this remains conjecture.

We close by noting an interpretation of our analysis that suggests a fruitful direction for future research. In the context of online marketplaces (cf. Levin, 2011), sequencing auctions and revealing future object information can be interpreted as aspects of what e-commerce firms call user-interface design. Surely there are other elements of user-interface design that have an important impact on market performance: helping users search for objects efficiently; helping sellers describe their objects effectively; reducing the transactions costs, for example, measured in user time, associated with performing various actions in the marketplace; and so on. Our paper perhaps represents a first foray into the economic analysis of this important aspect of online market design.

\footnotetext{
${ }^{13}$ Suppose we have three auctions instead of only two, with each bidder having private single-item valuations $\left(v_{1}, v_{2}, v_{3}\right)$, and suppose further that only the winner and the price $p_{1}$ of the first unit are revealed before the second stage. Then second-stage bidders have asymmetric beliefs about the $v_{3}$ of the remaining competitors, because one of the remaining bidders bid exactly $p_{1}$, whereas the other bidders bid strictly below $p_{1}$. Even when this asymmetry is resolved by revealing all first-stage bids, as suggested by Milgrom and Weber (2000), the information about future goods would make it necessary to explicitly model second-stage beliefs about $v_{3}$ : first-stage bids would be a function of $v_{3}$, and bidders thus may have an incentive to mislead their competitors into thinking their $v_{3}$ is very high by bidding very low in the first stage. Furthermore, the price $p_{1}$ would enter second-stage bids, so the last two auctions do not reduce to the environment studied here. Thus, even with just three auctions it is unclear whether there exist intuitive pure-strategy equilibria.
} 


\section{Appendix}

Definition: $S$ is said to be regular if $S\left(v_{2}, L_{1}\right)=0, S$ is continuous, and $S$ does not decrease in $c_{1}$ faster than unity.

Claim: When $S$ is regular, the FOC condition in equation (2) characterizes the best response function to $S$

Proof: The objective function shown in equation (1), which we will denote as $\Pi\left(\beta \mid v_{1}, v_{2}, S\right)$, is concave at the $F O C$ when $S$ does not decrease in $c_{1}$ faster than unity. Let $\beta_{F O C}$ be the value of $\beta$ implied by the FOC. When $S$ is partially differentiable, the $S O C$ is $\left.\frac{d^{2} \Pi}{d \beta^{2}}\right|_{\beta=\beta_{F O C}}=-1-\left.\frac{\partial S}{\partial \beta}\right|_{\beta=\beta_{F O C}}<\left.0 \Leftrightarrow \frac{\partial S}{\partial \beta}\right|_{\beta=\beta_{F O C}}>-1$. When $S$ is not partially differentiable, $S\left(v_{2}, d\right)-S\left(v_{2}, c\right)>(-1)(d-c)$ is sufficient for concavity of $\Pi\left(\beta \mid v_{1}, v_{2}, S\right)$ at the FOC. Although $\Pi$ may not be globally concave, the $F O C$ characterizes the global optimum of $\Pi$ because $v_{1}-\beta>S\left(v_{2}, \beta\right)$ iff $\beta<\beta_{F O C}$. This single-crossing property is again implied by regularity, as discussed next. To see that the $b_{1}\left(v_{1}, v_{2}\right)$ is well defined by the $F O C$, note that $S\left(v_{2}, d\right)-S\left(v_{2}, c\right)>(-1)(d-c)$ implies the RHS of equation (2) does not increase in $\beta$ faster than unity. $S\left(v_{2}, L_{1}\right)=0$ fixes the intercept of the RHS at $v_{1}-S\left(v_{2}, L_{1}\right)=v_{1} \geq L_{1}$. Since the LHS of equation (2) is an identity function, continuity of $S$ in $c_{1}$ implies (via the Intermediate Value Theorem) that the RHS must eventually intersect the LHS at some $\beta \geq L_{1}$ that solves equation (2). Such a solution is unique because the slope of $v_{1}-S\left(v_{2}, \beta\right)$ in $\beta$ is less than unity everywhere, so a second intersection is impossible.

The single crossing property outlined above also shows that abstaining from the first auction cannot be a profitable deviation. Suppose $N-1$ competitors bid according to $b_{1}(\cdot)$, and a focal bidder deviates to an abstention instead of bidding $B \equiv b_{1}\left(v_{1}, v_{2}\right)$. The only way such a deviation can make any difference in the outcome of the game is if the focal bidder would have won the first auction, that is, if $B>c_{1}$. For $B>c_{1}$, the deviation thus yields the expected second- 
stage surplus of $\int_{0}^{B} S\left(v_{2}, c_{1}\right) d G_{1}\left(c_{1}\right)$ instead of $\int_{0}^{B}\left(v_{1}-c_{1}\right) d G_{1}\left(c_{1}\right)$ available from bidding $B$. But the profit from the deviation must be lower, because $v_{1}-\beta>S\left(v_{2}, \beta\right)$ for all $\beta<B$. QED Claim.

\section{Figure A1: Bidding function is well defined by equation (2)}

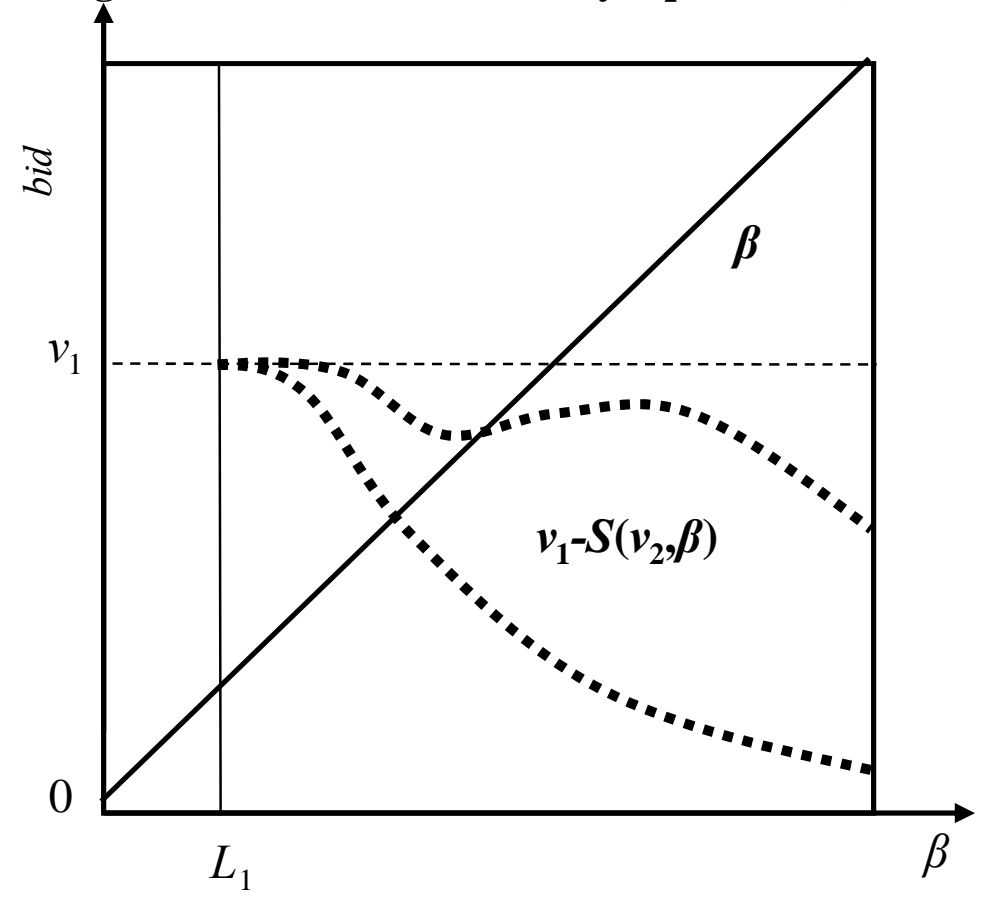

Note to Figure: The solid diagonal line is the LHS of equation (2). The two dashed lines illustrate two possible RHS of equation (2): the lower dashed line corresponds to $S$ increasing in bid-level; the upper dashed line corresponds to $S$ locally decreasing in bid-level, but slower than unity.

\section{Proof of Theorem 1}

We construct the equilibrium in three steps:

1) The full support and boundedness of $f$ imply that for every $\beta \in\left(L_{1}, H_{1}\right]$, a unique function $I$ exists that satisfies equation (4). This function is a candidate for an isobid curve $I\left(v_{2} \mid \beta\right)$.

2) The set of candidate isobids $I\left(v_{2} \mid \beta\right)$ for all $\beta \in\left(L_{1}, H_{1}\right]$ implies a candidate surplus function $S\left(v_{2}, c_{1}\right)=I\left(v_{2} \mid c_{1}\right)-c_{1}$. The full support and boundedness of $f$, together with the properties of the candidate isobids implied by equation (4), ensure that

A) For every $v_{2} \in\left[L_{2}, H_{2}\right], S$ does not decrease in $c_{1}$ faster than unity:

$$
\forall c<d \in\left(L_{1}, H_{1}\right), S\left(v_{2}, d\right)-S\left(v_{2}, c\right)>(-1)(d-c) .
$$

B) $S$ is continuous in $c_{1}$ on $c_{1} \in\left[L_{1}, H_{1}\right]$. 
C) For every $v_{2} \in\left[L_{2}, H_{2}\right], S\left(v_{2}, L_{1}\right)=0$.

3) Because $S$ satisfies A, B, and C, there is a unique best response function defined implicitly by $b_{1}\left(v_{1}, v_{2}\right)=v_{1}-S\left(v_{2}, b_{1}\left(v_{1}, v_{2}\right)\right)$, which is increasing in $v_{1}$. Therefore, the candidate isobids from Step 1 are indeed equilibrium isobids.

\section{Step 1: Existence and uniqueness of candidate isobids}

Claim 1: For each $c_{1} \in\left(L_{1}, H_{1}\right]$, there exists a unique nondecreasing 1-Lipschitz function $I\left(v_{2} \mid c_{1}\right):\left[L_{2}, H_{2}\right] \rightarrow\left[c_{1}, c_{1}+H_{2}-L_{2}\right]$ with $I\left(L_{2} \mid c_{1}\right)=c_{1}$ such that $I\left(L_{2} \mid c_{1}\right)=\boldsymbol{T}\left[I\left(L_{2} \mid c_{1}\right) \mid c_{1}\right]$.

Proof: Fix any $c_{1} \in\left(L_{1}, H_{1}\right)$ and denote the global bound on $f$ by $\bar{f}$. Let $B\left(c_{1}\right)$ be a set of nondecreasing 1-Lipschitz functions $I:\left[L_{2}, H_{2}\right] \rightarrow\left[c_{1}, c_{1}+H_{2}-L_{2}\right]$ such that $I\left(L_{2}\right)=c_{1}$ : $B\left(c_{1}\right)=\left\{I:\left[L_{2}, H_{2}\right] \rightarrow\left[c_{1}, c_{1}+H_{2}-L_{2}\right], I\left(L_{2}\right)=c_{1}, \forall x>y, 0 \leq I(x)-I(y)<x-y\right\}$. $B\left(c_{1}\right)$ is a closed subset of the complete metric space of all bounded continuous functions from $\left[L_{2}, H_{2}\right]$ to $\left[0, H_{1}+H_{2}-L_{2}\right]$ with the supremum metric $d(I, J)=\max _{v \in\left[L_{2}, H_{2}\right]}[|I(v)-J(v)|]$, so it is a complete metric space with the same metric. It is immediate from equation 2 that $\boldsymbol{T}$ projects $B\left(c_{1}\right)$ into itself: $\boldsymbol{T}: B\left(c_{1}\right) \rightarrow B\left(c_{1}\right)$. The remainder of the proof shows that for every $c_{1} \in\left(L_{1}, H_{1}\right)$, a $K \geq 1$ exists such that $\boldsymbol{T}^{K}(I)$ is a contraction map. That is, a $q<1$ exists such that $d\left(\boldsymbol{T}^{K}(I), \boldsymbol{T}^{K}(J)\right)<q d(I, J)$ for all $I, J \in B\left(c_{1}\right)$. By the Banach Fixed Point Theorem, this is enough to show that $\boldsymbol{T}$ has a unique fixed point in $B\left(c_{1}\right)$, and iterations of $\boldsymbol{T}$ starting at any point in $B\left(c_{1}\right)$ converge to the unique fixed point exponentially fast. The unique fixed point is the unique isobid $I\left(v_{2} \mid c_{1}\right)$.

It is enough to consider $N=3, d(\boldsymbol{T}(I), \boldsymbol{T}(J))$ obviously decreases in $N$. Pick any distance $\delta>0$ and any $I_{1} \in B\left(c_{1}\right)$. Let $I_{2}(v)=\underset{J \in B\left(c_{1}\right)}{\arg \max } d\left(\boldsymbol{T}^{K}\left(I_{1}\right), \boldsymbol{T}^{K}(J)\right)=I_{1}(v)+\min [\delta, v]$, and note that $d\left(\boldsymbol{T}^{K}\left(I_{1}\right), \boldsymbol{T}^{K}\left(I_{2}\right)\right)<d\left(\boldsymbol{T}^{K}\left(I_{1}\right), \boldsymbol{T}^{K}\left(I_{1}+\delta\right)\right)$. Therefore, it is sufficient to show $d\left(\boldsymbol{T}^{K}(I), \boldsymbol{T}^{K}(I+\delta)\right)<q \delta$ for some $q<1$. The following Lemma is critical for the result: 
Lemma $1: \forall \alpha \in R_{+}$\& integer $M \geq 0:\left|\boldsymbol{T}\left(I(x)+\frac{\alpha x^{M}}{M !}\right)(w)-\boldsymbol{T}(I(x))(w)\right|<\frac{\alpha \bar{f} w^{(M+2)}}{(M+2) ! F\left(c_{1}, 1\right)}$

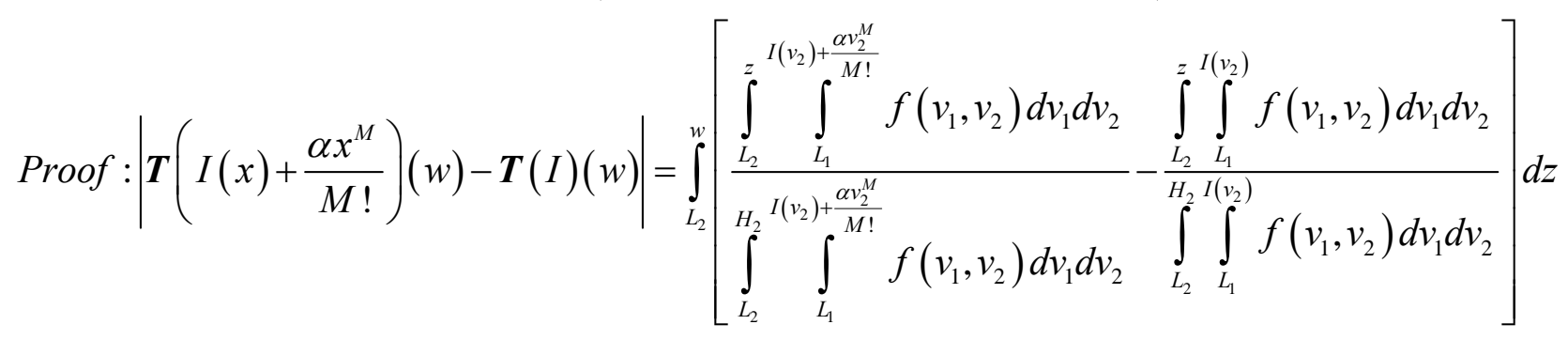

$<\frac{\int_{\left(I>c_{1}\right)}^{w} \int_{L_{2}}^{z} \int_{L_{2}}^{I\left(v_{2}\right)+\frac{\alpha v_{2}^{M}}{M !}} \int_{I\left(v_{2}\right)}^{M !} f\left(v_{1}, v_{2}\right) d v_{1} d v_{2} d z}{F\left(c_{1}, 1\right)}<\frac{\int_{(f<\bar{f})} \int_{L_{2}}^{w} \int_{L_{2}}^{z} \alpha \bar{f} \frac{v_{2}^{M}}{M !} d v_{2} d z}{F\left(c_{1}, 1\right)}<\frac{\alpha \bar{f} \int_{0}^{w} \int_{0}^{z} v_{2}^{M} d v_{2} d z}{M ! F\left(c_{1}, 1\right)}=\frac{\alpha \bar{f} w^{(M+2)}}{(M+2) ! F\left(c_{1}, 1\right)} Q E D$ L1

Lemma 1 shows that adding the polynomial function $\frac{\alpha x^{M}}{M !}$ to any curve in $B\left(c_{1}\right)$ and applying the $\boldsymbol{T}$ mapping results in images not too far apart from each other, with the distance at point $w$ bounded above by $\frac{\alpha \bar{f} w^{(M+2)}}{(M+2) ! F\left(c_{1}, 1\right)}$. Intuitively, the two images will be very close together for small $w$ and diverge from each other monotonically as $w$ increases. The intuition for the bound arises from the worst-possible scenario whereby there happens to be a lot of mass between the original curve $I(x)$ and $I(x)+\frac{\alpha x^{M}}{M !}$, and this mass is "integrated over" twice by definition of the $\boldsymbol{T}$ mapping.

Lemma 1 implies $\boldsymbol{T}$ may not be a contraction for small-enough $c_{1}$ : setting $\alpha=\delta$ and $M=0$ in Lemma 1 implies $d(\boldsymbol{T}(I), \boldsymbol{T}(I+\delta))=\left|\boldsymbol{T}(I)\left(H_{2}\right)-\boldsymbol{T}(I+\delta)\left(H_{2}\right)\right|<\frac{\delta \bar{f} H_{2}^{2}}{2 F\left(c_{1}, 1\right)}$, and $\frac{\delta \bar{f} H_{2}^{2}}{2 F\left(c_{1}, 1\right)}$ may not be less than unity. However, note that $\boldsymbol{T}$ bounds the difference between the images of $I$ and $I+\delta$ quadratically as a function of $v:|\boldsymbol{T}(I)(v)-\boldsymbol{T}(I+\delta)(v)|<\frac{\delta \bar{f}^{2}}{2 F\left(c_{1}, 1\right)}$. The quadratic bound strengthens to quartic when one applies $\boldsymbol{T}$ twice, that is, when $\boldsymbol{T}$ is applied to $\boldsymbol{T}(I+\delta)$ and $\boldsymbol{T}(I)$ : 
$\left|\boldsymbol{T}^{2}(I+\delta)(w)-\boldsymbol{T}^{2}(I)(w)\right|<\left|\boldsymbol{T}\left(J(v)+\frac{\delta \bar{f} v^{2}}{2 F\left(c_{1}, 1\right)}\right)(w)-\boldsymbol{T}(J(v))(w)\right|<\delta \frac{w^{4}}{4 !}\left(\frac{\bar{f} H_{2}^{2}}{F\left(c_{1}, 1\right)}\right)^{2}$,

where $\quad J=\boldsymbol{T}(I) . \quad$ By induction, $\quad d\left(\boldsymbol{T}^{K}(I), \boldsymbol{T}^{K}(I+\delta)\right)<\frac{\delta}{(2 K) !}\left(\frac{\bar{f} H_{2}^{2}}{F\left(c_{1}, 1\right)}\right)^{K}$. Since $\lim _{K \rightarrow \infty} \frac{C^{K}}{(2 K) !}=0$ for every positive constant $C$, this limit as $K$ grows proves a $K$ exists high enough that $\boldsymbol{T}^{K}$ is a contraction. QED Step 1.

\section{Step 2: Regularity of the expected surplus function implied by candidate isobids}

The full set of candidate isobids $\left\{I\left(v_{2} \mid c_{1}\right)\right\}_{c_{1}>L_{1}}^{H_{1}}$ from Proposition 3 implies a unique candidate for the expected surplus function defined on $\left[L_{2}, H_{2}\right] \times\left(L_{1}, H_{1}\right]: S\left(v_{2}, c_{1}\right)=I\left(v_{2} \mid c_{1}\right)-c_{1}$. Extend the surplus function to the entire closed support rectangle by defining it as a limit $S\left(v_{2}, L_{1}\right)=\lim _{c \rightarrow L_{1}} I\left(v_{2} \mid c\right)-L_{1} . S$ has the following properties stemming from the fact that $S$ is an integrated cumulative distribution function: $S\left(v_{2}, c_{1}\right) \geq 0, S$ is twice partially differentiable in $v_{2}$, $S$ is non-decreasing in $v_{2}$, 1-Lipschitz in $v_{2}$, and convex in $v_{2}$ :

$S\left(v_{2}, c_{1}\right)=\int_{L_{2}}^{v_{2}} G_{2}\left(c_{2} \mid c_{1}\right) d c_{2} \geq 0 \Rightarrow 1 \geq \frac{\partial S}{\partial v_{2}}=G_{2}\left(v_{2} \mid c_{1}\right) \geq 0 \Rightarrow \frac{\partial^{2} S}{\partial v_{2}^{2}}=\frac{\int_{L_{1}}^{I\left(v_{2} \mid c_{1}\right)} f\left(v_{1}, v_{2}\right) d v_{1}}{F\left[I\left(\cdot \mid c_{1}\right), H_{2}\right]} \geq 0$,

where all inequalities are strict when $v_{2}>L_{2}$. The intuition is straightforward: the expected surplus increases in the valuation $v_{2}$ because a higher valuation makes winning more likely and also increases the actual surplus conditional on winning. Since these two at-least-linearly increasing components effectively multiply to produce the expected surplus, the convexity results. Since increasing $v_{2}$ by a small amount can increase the expected future surplus at most by that amount (and that only in the case when future prices are guaranteed to be below $v_{2}$ ), the slope of $S$ in $v_{2}$ is bounded above by unity. The rest of Step 2 of the proof shows that $S$ is well behaved not only as a function of $v_{2}$, but also as a function of $c_{1}$. 
Claim 2A: $\forall c<d \in\left(L_{1}, H_{1}\right) \& \forall v_{2} \in\left[L_{2}, H_{2}\right], S\left(v_{2}, d\right)-S\left(v_{2}, c\right)>(-1)(d-c)$.

To show that $S$ does not decrease in $c_{1}$ faster than unity, it is enough to show that two candidates for equilibrium isobids cannot cross or even touch each other, that is, that $I\left(v_{2}, c_{1}\right)$ is strictly increasing in both arguments: $\forall c<d \in\left(L_{1}, H_{1}\right) \& \forall v \in\left[L_{2}, H_{2}\right]: d>c \Rightarrow I(v \mid d)>I(v \mid c)$.

Proof: Suppose there is a pair $d>c$ and a $\tilde{v} \in\left[L_{2}, H_{2}\right]$ such that $I(v \mid d) \leq I(v \mid c)$, and denote $I_{c}(v) \equiv I(v \mid c)$. Continuity of isobids implies that the two isobids must intersect at or below $\tilde{v}$. Let the smallest intersection point be $v^{*}$, namely, $I_{d}(v)>I_{c}(v)$ for all $v<v^{*}$ and $I_{d}\left(v^{*}\right)=I_{c}\left(v^{*}\right)$. Therefore, $I_{c}(v)$ intersects $I_{d}(v)$ from below at $v^{*}$, so the slope of $I_{c}(v)$ at $v^{*}$ must be weakly higher than the slope of $I_{d}(v)$ at $v^{*}: I_{c}^{\prime}\left(v^{*}\right) \geq I_{d}^{\prime}\left(v^{*}\right)$. Equilibrium and full support of $f$ rule this ordering of slopes at $v^{*}$ out. Three distinct cases exist:

Case 1: $I_{d}(v) \leq I_{c}(v)$ on $\left(v^{*}, H_{2}\right]$ (see dotted line in Figure A2 accompanying this proof). From equation $6, I_{b}^{\prime}\left(v^{*}\right)=G_{2}\left(v^{*} \mid I_{b}\right)=\left(\frac{F\left(I_{b}, v^{*}\right)}{F\left(I_{b}, H_{2}\right)}\right)^{N-2}$. Let $A=F\left(\min \left[I_{c}, I_{d}\right], H_{2}\right)$, $A 1=F\left(I_{c}, v^{*}\right)$, and $X=F\left(I_{d}, v^{*}\right)-F\left(I_{c}, v^{*}\right)$. From full support of $f, X>0$. Since $I_{d}(v) \leq I_{c}(v)$ on $\left(v^{*}, H_{2}\right], I_{d}^{\prime}\left(v^{*}\right)=\left(\frac{A 1+X}{A+X}\right)^{N-2}>\left(\frac{A 1}{A}\right)^{N-2} \geq\left(\frac{A 1}{A+B+Y}\right)^{N-2}=I_{c}^{\prime}\left(v^{*}\right)$, where $B+Y \geq 0$ is the probability mass between the two isobids on $\left(v^{*}, H_{2}\right]$, and it is non-negative because of full support and $I_{d}(v) \leq I_{c}(v) \quad$ on $\quad\left(v^{*}, H_{2}\right]$ : $B+Y=\left[F\left(I_{c}, H_{2}\right)-F\left(I_{c}, v^{*}\right)\right]-\left[F\left(I_{d}, H_{2}\right)-F\left(I_{d}, v^{*}\right)\right]$. This inequality based on the equilibrium relation is a contradiction with the ordering of slopes necessary for an intersection at $v^{*}$. Intuitively, a single intersection at $v^{*}$ forces the conditional probability of a $v_{2}<v^{*}$ greater for the higher and flatter isobid, and this conditional probability happens to be the slope of the isobid at $v^{*}$.

Case 2: Suppose the ordering of the isobids on $\left(v^{*}, H_{2}\right]$ is ambiguous. At least one more intersection must be at point $w^{*}>v^{*}$, and it must be true that $I_{c}^{\prime}\left(w^{*}\right) \leq I_{d}^{\prime}\left(w^{*}\right)$. For equilibrium isobids, the order of slopes at $v^{*}$ and the full support rule out this ordering of slopes at $w^{*}$. Let 
$A 2+B 1=F\left(I_{d}, w^{*}\right)-F\left(I_{d}, v^{*}\right), \quad Y=\left[F\left(I_{c}, w^{*}\right)-F\left(I_{c}, v^{*}\right)\right]-\left[F\left(I_{d}, w^{*}\right)-F\left(I_{d}, v^{*}\right)\right]$, and $Q=\left[F\left(I_{d}, H_{2}\right)-F\left(I_{d}, w^{*}\right)\right]-\left[F\left(I_{c}, H_{2}\right)-F\left(I_{c}, w^{*}\right)\right]$ (see Figure A2). From full support of $f$, $A 2+B 1>0$ and $Y>0$, but the sign of $Q$ is ambiguous. Nevertheless, we can express $I_{c}^{\prime}\left(v^{*}\right) \geq I_{d}^{\prime}\left(v^{*}\right)$ as $I_{c}^{\prime}\left(v^{*}\right)=\left(\frac{A 1}{A+B+Y}\right)^{N-2}>\left(\frac{A 1+X}{A+B+X+Q}\right)^{N-2}=I_{d}^{\prime}\left(v^{*}\right)$. To obtain the implied slopes at $w^{*}$, add $A 2+B 1+Y$ to the $L H S$ numerator and only $A 2+B 1$ to the $R H S$ numerator. These additions clearly preserve the inequality: $I_{c}^{\prime}\left(w^{*}\right)=\left(\frac{A 1+(A 2+B 1+Y)}{A+B+Y}\right)^{N-2}>\left(\frac{A 1+X+(A 2+B 1)}{A+B+X+Q}\right)^{N-2}=I_{d}^{\prime}\left(w^{*}\right)$. This is a contradiction with the necessary ordering of slopes for a second intersection at $w^{*}: I_{c}^{\prime}\left(w^{*}\right)<I_{d}^{\prime}\left(w^{*}\right)$.

Figure A2: Cases 1 and 2 of the $I\left(v_{2} \mid d\right)$ isobid in Claim 2A

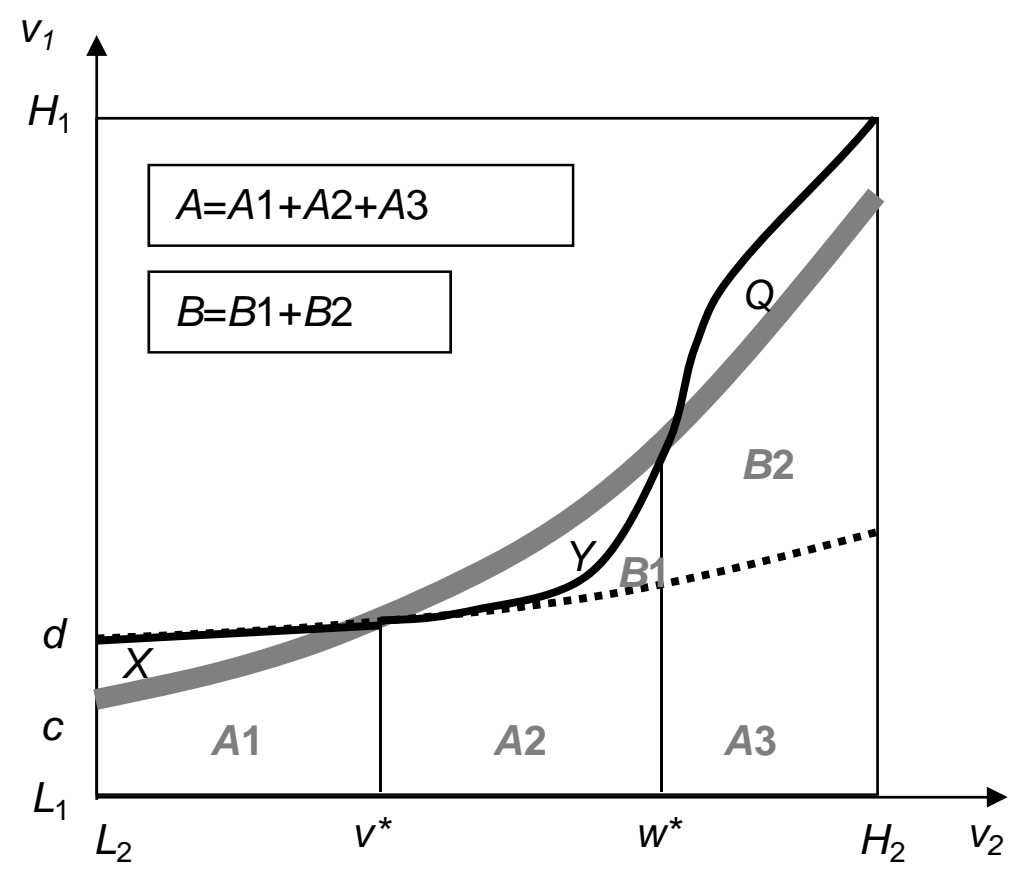

Note to Figure: The solid convex function is the $I\left(v_{2} \mid c\right)$ isobid. The dotted line is the Case 1 possibility for the $I\left(v_{2} \mid d\right)$ isobid, and the remainig solid line is Case 2 . All marked areas denote probability mass between curves.

Case 3: The only remaining possibility is that $v^{*}$ is in fact a point of tangency, namely, $I_{c}^{\prime}\left(v^{*}\right)=I_{d}^{\prime}\left(v^{*}\right)$ and $I_{d}(v)>I_{c}(v)$ everywhere other than at $v^{*}$. Since Cases 1 and 2 rule out any intersections, tangency at $v^{*}$ means the tangency holds for all $z \in[c, d]$, and the curvatures 
of all the $I_{z}$ at $v^{*}$ must be nondecreasing in $z: \frac{d I_{z}^{\prime \prime}\left(v^{*}\right)}{d z} \geq 0$. Once again, equilibrium implies this ordering of curvatures cannot happen: let the slope at $v^{*}$ be equal to some $\lambda$. Then for every $z \in[c, d], \frac{F^{N-2}\left(I_{z}, v^{*}\right)}{F^{N-2}\left(I_{z}, H_{2}\right)}=G_{2}\left(v^{*} \mid z\right)=\lambda$, so $I_{z}(v)=z+\lambda \int_{0}^{v} \frac{F^{N-2}\left(I_{z}, x\right)}{F^{N-2}\left(I_{z}, v^{*}\right)} d x$. Differentiate twice to obtain $I_{z}^{\prime \prime}(v)=\frac{\lambda(N-2) F^{N-3}\left(I_{z}, v\right)}{F^{N-2}\left(I_{z}, v^{*}\right)} \int_{L_{1}}^{I_{z}(v)} f\left(v_{1}, v_{2}\right) d v_{1} \Rightarrow I_{z}^{\prime \prime}\left(v^{*}\right)=\frac{\lambda(N-2)}{F\left(I_{z}, v^{*}\right)} \int_{L_{1}}^{I_{z}\left(v^{*}\right)} f\left(v_{1}, v_{2}\right) d v_{1}$. Since $I_{z}\left(v^{*}\right)$ is a constant for $z \in[c, d]$ and $F\left(I_{z}, v^{*}\right)$ strictly increases in $z$ because of full support, $I_{z}^{\prime \prime}\left(v^{*}\right)$ strictly decreases in $z$, a contradiction with $\frac{d I_{z}^{\prime \prime}\left(v^{*}\right)}{d z} \geq 0$. QED Claim $2 A$.

Claim 2B: $S$ is continuous in $c_{1}$ on $c_{1} \in\left[L_{1}, H_{1}\right]$.

We proceed in two sub-steps: first, we show that the candidate equilibrium surplus function $S\left(v_{2}, c_{1}\right)$ is continuous in $\mathrm{c}_{1}$ at all $c_{1} \in\left(L_{1}, H_{1}\right]$. By defining $I\left(v_{2} \mid L_{1}\right)$ as a limit, we extend the candidate surplus function to be continuous on the entire closed support $\left[L_{2}, H_{2}\right] \times\left[L_{1}, H_{1}\right]$.

To show that $S\left(v_{2}, c_{1}\right)$ is continuous in $\mathrm{c}_{1}$ at all $c_{1} \in\left(L_{1}, H_{1}\right]$, it is enough to show that $I\left(v_{2}, c_{1}\right)$ is upper semi-continuous at $c_{1}$, the proof of lower semi-continuity is analogous. Fix $c_{1}$ and consider any monotonically decreasing sequence of $\delta_{n}>0$ such that $\lim _{n \rightarrow \infty} \delta_{n}=0$. The corresponding sequence of isobids $\left\{I\left(v_{2} \mid c_{1}+\delta_{n}\right)\right\}_{n=1}^{\infty}$ is uniformly bounded because it projects into $\left[c_{1}, H_{1}+H_{2}-L_{2}\right]$, and it is equicontinuous because all isobids are nondecreasing and have slopes less than unity (1-Lipschitz). Therefore, the Arzela-Ascoli Theorem implies that $\left\{I\left(v_{2} \mid c_{1}+\delta_{n}\right)\right\}_{n=1}^{\infty}$ has a uniformly convergent subsequence, and its limit is some 1-Lipschitz function $I_{+}\left(v_{2} \mid c_{1}\right)$. Monotonicity of the original sequence (Claim 2A) implies that it also converges uniformly to $I_{+}\left(v_{2} \mid c_{1}\right)$, because when $I\left(v_{2} \mid c_{1}+\delta_{n}\right)$ is an element of the convergent subsequence, all $I\left(v_{2} \mid c_{1}+\delta_{n+k}\right)$ are between $I\left(v_{2} \mid c_{1}+\delta_{n}\right)$ and $I_{+}\left(v_{2} \mid c_{1}\right)$ in the supremum metric $d(I, J)=\max _{v \in\left[L_{2}, H_{2}\right]}[|I(v)-J(v)|]$ : for every $\varepsilon>0$, a $\bar{\delta}>0$ exists such that for every 
$\delta<\bar{\delta}, \quad d\left[I_{+}\left(\cdot \mid c_{1}\right), I\left(\cdot \mid c_{1}+\delta\right)\right]<\varepsilon . \quad$ Monotonicity further implies that for every $\delta$, $I\left(v_{2} \mid c_{1}\right) \leq I_{+}\left(v_{2} \mid c_{1}\right)<I\left(v_{2} \mid c_{1}+\delta\right)$.

That $I_{+}\left(v_{2} \mid c_{1}\right)=I\left(v_{2} \mid c_{1}\right)$ follows from $f$ having a bounded density $f<\bar{f}$ and from the uniqueness of isobids: the bounded density together with the uniform convergence of $\left\{I\left(v_{2} \mid c_{1}+\delta_{n}\right)\right\}_{n=1}^{\infty}$ implies that the implied sequence of distributions $\left\{G_{2}\left(c_{2} \mid c_{1}+\delta_{n}\right)\right\}_{n=1}^{\infty}$ also approaches the implied $G_{2}\left(c_{2} \mid I_{+}\left(c_{1}\right)\right)$ uniformly:

Pick any $\varepsilon>0$. Uniform convergence of isobids $\Rightarrow \exists \bar{\delta}$ be such that $\forall \delta<\bar{\delta}$, $\left|I\left(v_{2} \mid c_{1}+\delta\right)-I_{+}\left(v_{2} \mid c_{1}\right)\right|<\frac{F\left(c_{1}, H_{2}\right) \varepsilon}{\bar{f}\left(H_{2}-L_{2}\right)} . \forall \delta<\bar{\delta}$, this implies $\left|G_{2}\left(x \mid c_{1}+\delta\right)-G_{2}\left(x \mid I_{+}\right)\right|=$ $=\left|\left(\frac{F\left[I\left(\cdot \mid c_{1}+\delta\right), x\right]}{F\left[I\left(\cdot \mid c_{1}+\delta\right), H_{2}\right]}\right)^{N-2}-\left(\frac{F\left[I_{+}\left(\cdot \mid c_{1}\right), x\right]}{F\left[I_{+}\left(\cdot \mid c_{1}\right), H_{2}\right]}\right)^{N-2}\right|<\left|\frac{F\left[I\left(\cdot \mid c_{1}+\delta\right), x\right]}{F\left[I\left(\cdot \mid c_{1}+\delta\right), H_{2}\right]}-\frac{F\left[I_{+}\left(\cdot \mid c_{1}\right), x\right]}{F\left[I_{+}\left(\cdot \mid c_{1}\right), H_{2}\right]}\right|<$

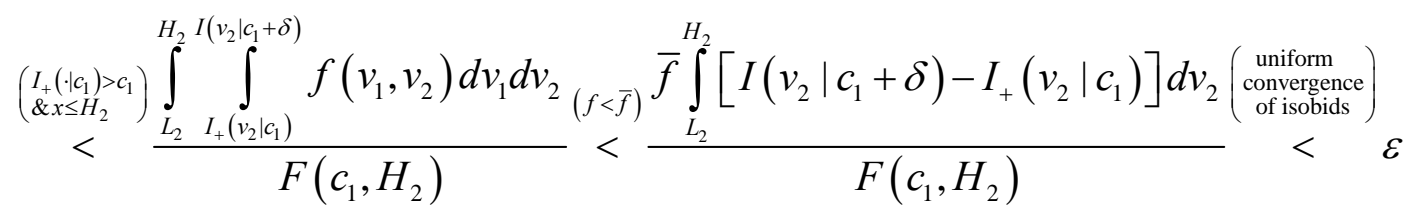

The uniform convergence of $\left\{G_{2}\left(c_{2} \mid c_{1}+\delta_{n}\right)\right\}_{n=1}^{\infty}$ in turn implies that the equilibrium relation from equation (4) $I\left(v_{2} \mid c_{1}+\delta\right)=\boldsymbol{T}\left[I\left(v_{2} \mid c_{1}+\delta\right) \mid c_{1}+\delta\right]$, which holds for every member of the sequence, is preserved in the limit:

$$
\begin{aligned}
I_{+}\left(v_{2} \mid c_{1}\right) & =\lim _{\delta \rightarrow 0} I\left(L_{2} \mid c_{1}+\delta\right)+\lim _{\delta \rightarrow 0} \int_{0}^{v_{2}} G_{2}^{N-2}\left(x \mid c_{1}+\delta\right) d x= \\
& =c_{1}+\int_{0}^{v_{2}} \lim _{\delta \rightarrow 0} G_{2}^{N-2}\left(x \mid c_{1}+\delta\right) d x=\boldsymbol{T}\left[I_{+}\left(v_{2} \mid c_{1}\right) \mid c_{1}\right]
\end{aligned}
$$

Since $I_{+}\left(v_{2} \mid c_{1}\right)=\boldsymbol{T}\left[I_{+}\left(v_{2} \mid c_{1}\right) \mid c_{1}\right]$, it must be true that $I_{+}\left(v_{2} \mid c_{1}\right)=I\left(v_{2} \mid c_{1}\right)$, because each isobid is unique (Claim 1). QED Claim $2 B$. 
Claim 2C: $\lim _{c \rightarrow L_{1}+} S\left(v_{2}, c_{1}\right)=0$.

The equilibrium condition (4) is not defined for the function $I\left(v_{2} \mid L_{1}\right)=L_{1}$, because the mass below it is zero. To derive the equilibrium restriction for such an isobid, multiply equation (4) by the probability mass under the isobid and differentiate the result twice (suppressing $c_{1}$ for clarity):

$I^{\prime \prime}\left(v_{2}\right) F^{N-2}\left(I, H_{2}\right)=(N-2) F^{N-3}\left(I, v_{2}\right) \int_{L_{1}}^{I\left(v_{2}\right)} f\left(v_{1}, v_{2}\right) d v_{1}$ such that $I\left(L_{2}\right)=c_{1}, I^{\prime}\left(L_{2}\right)=0$.

This alternative equilibrium condition holds, so $b_{1}\left(L_{1}, v_{2}\right)=L_{1}$ is a candidate for an equilibrium isobid. We now show that $b_{1}\left(L_{1}, v_{2}\right)=L_{1}$ is a unique candidate, and that higher $I\left(v_{2} \mid c_{1}\right)$ converge to it. By the same arguments used above, any monotonic sequence $\left\{I\left(v_{2} \mid L_{1}+\delta_{n}\right)\right\}_{n=1}^{\infty}$ converges uniformly to some 1-Lipschitz function $J\left(v_{2}\right)$ such that $L_{1} \leq J\left(v_{2}\right)<I\left(v_{2} \mid L_{1}+\delta\right)$ and $J\left(L_{2}\right)=L_{1}$. This proof shows that $J\left(v_{2}\right)$ must be the constant function $J\left(v_{2}\right)=L_{1}$. Suppose $J\left(v_{2}\right)>L_{1}$ for some $v_{2}>L_{2}$, so there is a positive mass under $J: F\left(J, H_{2}\right)>0$ (from continuity of $J$ together with full support of $f) . F\left(J, H_{2}\right)>0$ in turn implies that the RHS equation (4) is well defined, so $J=\boldsymbol{T}\left(J \mid L_{1}\right)$; that is, $J$ is a valid isobid for the bid-level $L_{1}$. The rest of this proof shows no $J:\left[L_{2}, H_{2}\right] \rightarrow\left[L_{1}, L_{1}+H_{2}-L_{2}\right]$ can exist such that $F\left(J, H_{2}\right)>0$, and $J=\boldsymbol{T}\left(J \mid L_{1}\right)$. The following Lemma 2 is crucial for proving the impossibility:

Lemma 2: Suppose $F\left(J, H_{2}\right)>A>0$ and $0<f<\bar{f}$. Then, $\forall \alpha \in R_{+}$\& integer $M \geq 0$ :

$$
J\left(v_{2}\right) \leq L_{1}+\alpha \frac{v_{2}^{M}}{M !} \Rightarrow \boldsymbol{T}\left(J \mid L_{1}\right)\left(v_{2}\right)<L_{1}+\left(\frac{\alpha \bar{f}}{A}\right) \frac{v_{2}^{M+2}}{(M+2) !}
$$

Proof of Lemma 2: $\boldsymbol{T}\left(J \mid L_{1}\right)\left(v_{2}\right)=L_{1}+\frac{\int_{L_{2}}^{v_{2}} \int_{L_{2}}^{z} \int_{L_{1}}^{J(w)} f\left(v_{1}, w\right) d v_{1} d w d z\left(\begin{array}{l}F\left(J, H_{2}\right)>A \\ J\left(v_{2}\right) \leq L_{1}+\alpha \frac{v_{2}^{M}}{M !}\end{array}\right)}{F\left(J, H_{2}\right)}<<$ $<L_{1}+\frac{\int_{L_{2}}^{v_{2}} \int_{L_{2}}^{z} \int_{L_{1}}^{L_{1}+\alpha \frac{w^{M}}{M !}} f\left(v_{1}, w\right) d v_{1} d w d z}{A} \stackrel{\substack{f<\bar{f} \\ L_{2} \geq 0}}{<} L_{1}+\frac{\alpha \bar{f}}{A} \int_{0}^{v_{2}} \int_{0}^{z} \frac{w^{M}}{M !} d w d z=L_{1}+\left(\frac{\alpha \bar{f}}{A}\right) \frac{v_{2}^{M+2}}{(M+2) !}$ 
Lemma 2 implies successive applications of $\boldsymbol{T}\left(\cdot \mid L_{1}\right)$ must eventually contract $J$ arbitrarily close to $L_{1}$-a contradiction with a fixed point of $\boldsymbol{T}\left(\cdot \mid L_{1}\right)$ satisfying $F\left(J, H_{2}\right)>A>0$ : from $J\left(v_{2}\right)$ being a 1-Lipschitz function, $J\left(v_{2}\right) \leq L_{1}+v_{2}$. Therefore,

$$
\begin{aligned}
& J\left(v_{2}\right) \leq L_{1}+v_{2} \Rightarrow \boldsymbol{T}\left(J \mid L_{1}\right)\left(v_{2}\right)<L_{1}+\left(\frac{\bar{f}}{A}\right) \frac{v_{2}^{3}}{3 !} \Rightarrow \boldsymbol{T}^{2}\left(J \mid L_{1}\right)\left(v_{2}\right)<L_{1}+\left(\frac{\bar{f}}{A}\right)^{2} \frac{v_{2}^{5}}{5 !} \ldots \\
& \stackrel{\text { (induction) }}{\Rightarrow} \boldsymbol{T}^{K}\left(J \mid L_{1}\right)\left(v_{2}\right)<L_{1}+\left(\frac{\bar{f}}{A}\right)^{K} \frac{v_{2}^{2 K+1}}{(2 K+1) !} \Rightarrow \forall v_{2} \in\left[L_{2}, H_{2}\right]: \lim _{K \rightarrow \infty} \boldsymbol{T}^{K}\left(J \mid L_{1}\right)\left(v_{2}\right)=0
\end{aligned}
$$

Note that a crucial difference exists between Lemmas 1 and 2: Lemma 1 shows that for $c_{1}>L_{1}$, enough repetitions of $\boldsymbol{T}\left(\cdot \mid c_{1}\right)$ eventually contract the images of two_candidate functions $\boldsymbol{T}^{K}\left(I_{1} \mid c_{1}\right)$ and $\boldsymbol{T}^{K}\left(I_{2} \mid c_{1}\right)$ to be closer to each other (in the supremum metric) than $I_{1}$ and $I_{2}$. In contrast, Lemma 2 shows that for $c_{1}=L_{1}$, enough repetitions of $\boldsymbol{T}\left(\cdot \mid c_{1}\right)$ eventually contract the image of any single candidate function $I_{1}$ to be arbitrarily close to $L_{1}$. However, $L_{1}$ is not a fixed point of $\boldsymbol{T}\left(\cdot \mid L_{1}\right)$ because $\boldsymbol{T}\left(L_{1} \mid L_{1}\right)$ is not defined: $\boldsymbol{T}\left(\cdot \mid L_{1}\right)$ is not a continuous function on the space of 1-Lipschitz functions $J:\left[L_{2}, H_{2}\right] \rightarrow\left[L_{1}, L_{1}+H_{2}-L_{2}\right]$. QED Claim $2 C$.

Step 3: there is a unique best response function defined implicitly by $b_{1}\left(v_{1}, v_{2}\right)=v_{1}-S\left(v_{2}, b_{1}\left(v_{1}, v_{2}\right)\right)$, which is increasing in $v_{1}$.

Claims 1 and 2 show that there is a unique $S\left(v_{2}, c_{1}\right)$ on $\left[L_{2}, H_{2}\right] \times\left[L_{1}, H_{1}\right]$ with properties A, B, and C. Therefore, equation (2) characterizes the best response to $S$ that satisfies

$$
b_{1}\left(v_{1}, v_{2}\right)=v_{1}-S\left(v_{2}, b_{1}\left(v_{1}, v_{2}\right)\right)
$$

We now describe the properties of $b_{1}$ : First, $b_{1}\left(L_{1}, v_{2}\right)=L_{1}$ because property $\mathrm{C}$ implies $L_{1}=L_{1}-S\left(v_{2}, L_{1}\right)$. Second, the fact that $S\left(v_{2}, c_{1}\right)$ is an integrated cdf implies $b_{1}\left(v_{1}, L_{2}\right)=v_{1}$ and $v_{1}>b_{1}\left(v_{1}, v_{2}\right)>L_{1}$ away from $\left(L_{1}, L_{2}\right)$. Third, suppose for simplicity that $S$ is partially differentiable in $c_{1}$, and implicitly differentiate of the first-order condition (2): $\frac{\partial b_{1}}{\partial v_{2}}=-\frac{\partial S}{\partial v_{2}} /\left(1+\left.\frac{\partial S}{\partial c_{1}}\right|_{c_{1}=b_{1}}\right)<0$ away from $\left(L_{1}, L_{2}\right)$ because the numerator is negative by convexity of $S$ in $v_{2}$ (and the denominator is positive by part A). Similarly, 
$\frac{\partial b_{1}}{\partial v_{1}}=\left(1+\left.\frac{\partial S}{\partial c_{1}}\right|_{c_{1}=b_{1}}\right)^{-1}>0$, so $b_{1}\left(v_{1}, v_{2}\right)$ is increasing in $v_{1}$ but not necessarily at a constant speed equal to unity. This confirms that the equilibrium is strictly monotone. The curvature of $b_{1}\left(v_{1}, v_{2}\right)$ is ambiguous. QED Step 3.

QED Theorem 1

Example: Three bidders, $\boldsymbol{f}$ uniform on $[0,1] \times[0, K]$

The uniform distribution simplifies the integral under an isobid to $\int_{0}^{I\left(v_{2} \mid c_{1}\right)} f\left(v_{1}, v_{2}\right) d v_{1}=\frac{\min \left[I\left(v_{2} \mid c_{1}\right), 1\right]}{K}$. Three bidders simplify the equilibrium condition (2') because the crucial exponent is $N-2=1$. There are two cases, depending on whether $I\left(K \mid c_{1}\right)<1$ (the upper bound of $v_{1}$ ).

Case 1: $c_{1}$ low enough that $I\left(K \mid c_{1}\right)<1$ : suppressing the conditioning on $c_{1}$ for clarity, equation (2') becomes $I^{\prime \prime}(v) \int_{0}^{K} I(x) d x=I(v)$ with initial conditions $I(0)=c_{1}, I^{\prime}(0)=0$. This differential-integral equation has a unique solution for every $c_{1}$ obtained as follows. First, solve a simpler differential equation $I^{\prime \prime}(v)\left(1 / A^{2}\right)=I(v)$ with $I(0)=c_{1}, I^{\prime}(0)=0$ for an arbitrary constant $A$. This simpler differential equation has a unique solution of $I(v)=c_{1} \cosh (A v)$, which integrates to $\int_{0}^{K} I(v) d v=\frac{c_{1} \sinh (K A)}{A}$. Therefore, the solution to (2') can be characterized as $I(v)=c_{1} \cosh \left[A\left(c_{1}\right) v\right]$, where the function $A\left(c_{1}\right)$ satisfies $1=c_{1} A\left(c_{1}\right) \sinh \left(K A\left(c_{1}\right)\right)$. The implicitly defined function $A\left(c_{1}\right)$ exists because $A \sinh (K A)$ is continuous, monotonically increasing on $[0, \infty)$, zero at $A=0$, and rising without bound as $A$ approaches infinity.

Case 2: $c_{1}$ high enough that $c_{1} \cosh \left[A\left(c_{1}\right) K\right]>1$ for the above-defined function $A\left(c_{1}\right)$. Fix $c_{1}$ again and suppress conditioning on it from notation. There is now a point $L_{2}<v^{*}<H_{2}$ 
such that $I\left(v^{*}\right)=1$, and the differential-integral equation (2') needs to acknowledge the support of $f$ in $F^{N-2}\left(I, H_{2}\right)$. For $v_{2}<v^{*}$, the equation is $I^{\prime \prime}\left(v_{2}\right)\left[\frac{1}{K} \int_{0}^{v^{*}} I\left(v_{2}\right) d v_{2}+\left(1-\frac{v^{*}}{K}\right)\right]=\frac{I\left(v_{2}\right)}{K} \Leftrightarrow I^{\prime \prime}\left(v_{2}\right)\left[\int_{0}^{v^{*}} I\left(v_{2}\right) d v_{2}+K-v^{*}\right]=I\left(v_{2}\right)$, with initial conditions $I(0)=c_{1}, I^{\prime}(0)=0$. Arguments analogous to Case 1 imply that $I\left(v_{2}\right)=c_{1} \cosh \left(B v_{2}\right)$ for some constant $B$ such that $\int_{0}^{v^{*}} I\left(v_{2}\right) d v_{2}+K-v^{*}=\frac{1}{B^{2}}$. The cutoff value is $v^{*}=\frac{\operatorname{arcsech}\left(c_{1}\right)}{B}$. The integral of $I 0$ to $v^{*}$ simplifies to $\int_{0}^{v^{*}} I\left(v_{2}\right) d v_{2}=\frac{c_{1}}{B} \int_{0}^{\operatorname{arcsech}\left(c_{1}\right)} \cosh (z) d z=\frac{\sqrt{1-c_{1}^{2}}}{B}$. To find the constant $B$, we need to make sure that $K-\frac{\operatorname{arcsech}\left(c_{1}\right)-\sqrt{1-c_{1}^{2}}}{B}=\frac{1}{B^{2}}$, which transforms to $K B-\frac{1}{B}=\log \left(1+\sqrt{1-c_{1}^{2}}\right)-\log \left(c_{1}\right)-\sqrt{1-c_{1}^{2}}$. The implicitly defined function $B\left(c_{1}\right)$ exists because the RHS is positive, setting $B=1 / \sqrt{K}$ makes LHS=0, and the LHS then increases without bound for $B>1 / \sqrt{K}$. Therefore, there is a unique $B$ such that LHS=RHS. 


\section{References}

Beggs, Alan and Kathryn Graddy, 1997. "Declining Values and the Afternoon Effect: Evidence from Art Auctions." RAND Journal of Economics, 28(3), 544-65.

Bergemann, Dirk and Johannes Horner. 2010. Should Auctions be Transparent? Cowles Foundation Working Paper.

Black, Jane, and David de Meza. 1992. Systematic Price Differences between Successive Auctions are no Anomaly. Journal of Economics and Management Strategy 1 (4): 607-8.

Board, Simon 2009. Revealing information in auctions: the allocation effect. Economic Theory 38:125-135

Budish, Eric. 2008. Sequencing and Information Revelation in Auctions for Imperfect Substitutes: Understanding eBay’s Market Design. Working paper. Harvard University.

Bulow, Jeremy and Paul Klemperer. 1996. Auctions versus Negotiations. American Economic Review. 86(1), 180-194.

Che, Yeon-Koo, and Ian Gale. 1998. Standard Auctions with Financially Constrained Bidders. Review of Economic Studies 65 (1): 1-21.

Cohen, Jane and Bob Grossweiner, 2006. "Industry Profile: Jeff Fluhr." Celebrity Access, October 9, accessed on www.stubhub.com.

Engelbrecht-Wiggans, Richard. 1994. Sequential Auctions of Stochastically Equivalent Objects. Economic Letters 44: 87-90.

Gale, Ian L., and Donald B. Hausch. 1994. Bottom-Fishing and Declining Prices in Sequential Auctions. Games and Economic Behavior 7: 318-31.

Haruvy, E. and P. T. L. Popkowski Leszczyc. 2010. Search and Choice in Online Consumer Auctions. Marketing Science 29(6): 1152-1164.

Holt, Charles A. and Roger Sherman. 1994. The Loser's Curse. American Economic Review 84(3): 642-52.

Jehiel, Philippe and Benny Moldovanu. 2000. Auctions with downstream interaction among buyers, RAND Journal of Economics 31 : 768-791.

Jofre-Bonet, Mireia, and Martin Pesendorfer. 2003. Estimation of a Dynamic Auction Game. Econometrica 71: 1443-89.

Kambil, Ajit and Eric van Heck, 1998. Reengineering the Dutch flower auctions: a framework for analyzing exchange organizations. Information Systems Research 9 (1): 1-19. 
Katzman, Brett. 1999. A Two-Stage Sequential Auction with Multi-Unit Demands. Journal of Economic Theory 86: 77-99.

Kim, Kyoo il and Joonsuk Lee. 2009. A Structural Analysis of Wholesale Used-Car Auctions, working paper. University of Minnesota.

Krishna, Vijay. 2002. Auction Theory. Academic Press of Elsevier Science, London, UK.

Levin, Jonathan. 2011. The Economics of Internet Markets. Forthcoming, Advances in Economics and Econometrics, Edited by D. Acemoglu, M. Arellano, and E. Dekel.

McAfee, Preston and John McMillan, 1987. "Auctions with Entry." Economics Letters, 23, 343-7.

Milgrom, Paul R., and Robert Weber. 2000. A Theory of Auctions and Competitive Bidding II. Working paper in 1982, now published in: Klemperer, P. (ed.), The Economic Theory of Auctions. Cheltenham, UK: Paul, Edward Elgar Publishing.

Pesendorfer, Wolfgang and Jeroen M. Swinkels. 1997. The Loser's Curse and Information Aggregation in Common Value Auctions. Econometrica 65(6) : 1247-1281

Reiß, J. Philipp and Schöndube, Jens Robert. 2008. First-price equilibrium and revenue equivalence in a sequential procurement auction model. Economic Theory, forthcoming.

Roth, Alvin E. and Axel Ockenfels. 2001. Last-Minute Bidding and the Rules for Ending Second-Price Auctions. American Economic Review. 92(4), 1093-1103.

Vickrey, William. 1961. Counterspeculation, Auctions, and Competitive Sealed Tenders. Journal of Finance 16(1): 8-37.

Zeithammer, Robert. 2005. Sequential Auctions with Information about Future Goods. Working Paper. University of Chicago.

Zeithammer, Robert. 2006. Forward-Looking Bidding in Online Auctions. Journal of Marketing Research 43(3): 462-76. 